\title{
European Integration and Europeanization Processes in Welfare Systems: A Comparative Analysis with Typological Purpose
}

\author{
Gabriella Punziano \\ Urban Studies Unit, Gran Sasso Science Institute, Italy
}

Copyright $(2016$ by authors, all rights reserved. Authors agree that this article remains permanently open access under the terms of the Creative Commons Attribution License 4.0 International License

\begin{abstract}
European Integration and Europeanization processes in social field are the focus of the analysis here proposed. Starting from the social implications and from the effects that the different European welfare regimes have on them, it will be shown a possible re-arrangement of the differences within the various regimes, as well as of their relationships and their new characterizations. The aim is highlight the dual thrust between Europeanization and decentralization of social policy in some European countries, which are considered as a guidance of specific welfare regimes, in order to understand at what level of governance the decisions that shape this area can be attributed. However, the analysis involved five Nations (Italy, Germany, France, Spain and United Kingdom) and ten local contexts, two for each Nation (Milan and Naples, Berlin and Munich, Paris and Rouen, Barcelona and Vigo, London and Liverpool). What result is a comparative geographic and policy analysis based on a mixed methods approach intended as a merge of quantitative and qualitative approaches, techniques and tools. The analysis contemplates jointly the study of supranational, national and subnational directions, but also the study of local dynamics concerning the spread of specific: models of implementation, kind of decision-making processes in social policies and type of regimes that this decision generates. The structure of the study is growing both in macro perspective (through multivariate and multi-level analysis of social indicators and subsequent cluster analysis) as well as in the micro perspective (through the analysis of projects in different local contexts and in particular by applying impact, implementation and comparative network analysis). The conclusion was the realization of a general model of interpretation and classification of the changes occurred in the different European welfare regimes.
\end{abstract}

Keywords Europeanization, European Integration, Social Policy, Welfare Regimes, Comparative Network Analysis

\section{Introduction}

European Integration and Europeanization processes, which have had their engine in political and economic instances, but whit direct effect on social field, are the focus of the analysis here proposed. In fact, it is starting from the social implication and from the answer that the different European welfare regimes give to these that it is show a possible re-arrangement and theming of the differences within the various regimes, their relationships and their new characterizations.

The starting point of the proposed reasoning is found in a previous study conducted for my doctoral dissertation: Unique European Welfare or Local Net Welfares: Decision-making process between convergence and autonomy [1]. With this study it was intended to deepen the dual thrust between Europeanisation and decentralization of social policy in some European countries, considerable guidance of specific welfare regimes [2], to understand at what level of governance are attributable to the decisions that shape this area. This objective was pursued through a comparative geographic and policy analysis based on a mixed methods approach intended as a merge of standard and non-standard approaches, techniques and tools. It means contemplate jointly the supranational, national and subnational directions and dynamics in the dissemination of specific models of implementation and decision of social policy and to the schemes which these decisions give life. This kind of methodological structure is growing both in macro perspective (through multivariate and multi-level analysis of Eurostat - Eu-silk dataset - and OECD territorial and social indicators, with subsequent cluster analysis) as well in the micro perspective (through the analysis of projects in different local contexts and in particular by applying impact, implementation and comparative social network analysis). Therefore, while the analysis of databases aimed at comparison of 27 European nations, the analysis of project was involved in five Nations (Italy, Germany, France, 
Spain and United Kingdom) and ten local contexts, two for each Nation (Milan and Naples, Berlin and Munich, Paris and Rouen, Barcelona and Vigo, London and Liverpool).

The conclusion was the realization of a general model of interpretation and classification of changes occurred in the different European welfare regimes. Classification that needs of further empirical testing in order to be included in the model also systems as well as Scandinavian or of Eastern European Country. Below we will present, together to the theoretical and methodological assumptions, the macro and the micro models with their opening questions, procedures and main empirical results.

\section{Theoretical and Methodological Assumptions}

The concept of Europeanization, in the middle of numerous studies on the changes in welfare regimes and on the dynamics of governance in the European Union $[3][4][5][6][7][8][9][10][11]$, can be seen in a multiple and otherwise acting meaning on the respective operative contexts on which it accounts.

In the relations between EU institutions and member states, this concept concerns the European integration process and the development of multilevel governance aimed to a full convergence towards a unitary system of government of social policies approved throughout the EU and based essentially on the principles of subsidiarity and activation of actors and context [12]. This acts on the single national political systems, which, in turn, respond by showing different degrees of intensity and adaptation in complying with the scenario outlined.

If we consider the same concept starting from the local contexts, that are seen as different branch centers of social governance in a decentralized manner, rather than starting from the hub of community interest (the supranational actor, Europe) are called into question the dynamics of implementation and decision-making that are designed to the expression of local autonomy in the social policies process of governance, undertaken in many ways, however addressed to the convergence [13].

Different from the concept of Europeanization is that of European integration which, according to Giuliani [14], refers to something of extremely legal, regulatory and procedural meaning, that capture macro dynamics and relationships of system, while with the Europeanization concept we refer explicitly to micro dynamic originated from a silent, differentiated and often contradictory process detectable in the processes of governance, and in which are the actors that decide and give shape to the different emerging structuring [15]. The Europeanization can be understood as a process through which the European Union structures, procedures and policies are specialize and automate from the national level, as well as it happen for more general process of institutionalization of the European
Union itself [16] and of its governance structures. In facts, the institutionalization becomes the hallmark and also the point of union between a conception of community integration, with regulatory meaning, and a conception of Europeanization, with procedural meaning. This link becomes clear especially in the transition from an hard to a soft law legislation in the field of social policies between the different levels of governance (supranational, national and local). The process of Europeanization focuses on strategic convergence towards full EU integration which is pursued, however, through decentralized mechanisms, subsidiarity and open method of coordination that is aimed to revalue the territorial dimension of social policy. The auspicious integration on the bottom of this process will be realized essentially in two directions. A kind of integration directed to the context (more often identified into social and territorial cohesion policy), which points to reevaluate and make it competitive and able to face the global challenges, and a kind of integration facing to the person (identified with social inclusion policies), which are, instead, aims to guarantee common standards of living and to invest on individuals for making them an active part of the inclusion and participatory process (place and people) [17]. Two different ways of conceiving the process of integration not always fully reconciled and it because of the scarcity of resources to invest in the social as well as the involvement of different stakeholders that this process can implied. The factor that drives these forces is to be found in the ability of contexts, either national or local, to move towards a full EU integration (unique European welfare system) or diverge from it (local net welfare systems). The EU integration variable becomes, therefore, the discriminant one in reconsider, through a comparative study, a different typology of welfare regimes built on the gradual integration, the differential convergence strategy and the recovery of implementation autonomous spaces, factors that push to a unitary system or to multiple local systems. A typology more focused on the role played by the European regulatory level as managerial and address actor of welfare policies [18], far from the classical conceptions based on the ownership of the right to provide social intervention, on the more or less pervasive intervention of the National State, spending levels, access requirements, the coverage funding, the recipients or the criteria for the award of disbursement, as well as on the mix of actors involved in local governance [19] [20] [21] [22] [23]. It because in this historical moment in a generalized way the welfare systems was passed from monetary disbursement to the provision of services, from dependency to activation, from self-exclusion to self-employment, strengthening of capabilities and competitive capacity first of individuals and then of the system that they make up [24], from a straight and pervasive action of the National State to the emergence of other social actors (Third Sector, Family, the private social, etc. $)^{1}$, more often defined welfare mix [30].

$1[25][26][27][28][29]$. 
This process of change, supported by demographic, social and economic change in the member Countries, as well as the passage from the law-making of exclusive competence of the State in the social field to an orientated legislative agency entrusted to the bodies of the Union (also detected in the passage from soft to hard law legislation), which led the welfare states to become a consolidate dimension of the solidarity and sharing of risk system [31].

One wonders, therefore, from that point spread, and how the decisions are take in the social field. Thus outlined, this question brings into play several levels of analysis and more analytic objects that require, for their conjunction, an integrated approach, not necessarily convergent, and which allows to investigate the field of the analysis than in macro that in micro perspective. This approach is represented by Mixed Methods [32] [33] [34]; an integrated approach of methods, techniques and tools aimed to the elaboration of an interpretive and knowledge tool that becomes itself the result, pursuing different strategies both on the standard then on the non-standard side. The mechanism method essential for the integration in this kind of mix strategy has been identified in the translation of both languages, standard and non-standard, in a common code. What ensues is the construction of the general model of classification, main result of the analysis conducted, in which every result that emerged from the different analytical step has been transformed into characteristics and attributes that substantiate the different types emerged and they can live together, in this way, without particular ontological and epistemological issues, in a flexible, dynamic and ever changing multi-methods model, because it integrates the change in the system under investigation as a systemic variable. This integrated approach don't aspire to bring into question the efficacy of classic typology, but intends to offer new opportunities to bring out details unmanageable or undetectable when the reality investigated is vast for extension, history and cultural heritage (as in the case of Europe), but even more when what we want is to break up this reality and put it in a comparative design. To approach this complexity, the pattern of analysis used was divided into sequential steps that will be followed described and that are built one inside the other as a sub-designs within the overall more complex design (nested) [35], which takes the name of Complex Mixed Methods Design [36]. Postponing the discussion elsewhere on the mathematical and statistical technical details of the model proposed [37], here we discussed the main objectives and results achieved.

\section{The Typological Axes}

The first step of analysis, aimed to the emergence of the axes underlying the typology in the general model of classification, since from the initial phase of the study, was characterized by the recovery of a policy comparative approach which didn't replaced but integrated geographical comparisons. These two method characterizations are going to fit on the delimitation of the typological axes binding to the possibility of covering the two plans, semantic and spatial, into the multiple levels reality considered in this study. A semantic continuum (vertical axis), defined as the EU Integrational axis and generated in the opposition between the two poles of development, social inclusion and territorial cohesion, in a methodological approach centered, precisely, on the policy comparison. A spatial continuum (horizontal axis), which is based, instead, on the geographical comparisons, impregnated by developments and by evolutionary dynamics of welfare systems (Europeanization vs. Decentralization, Convergence vs. local Autonomy) that finish to stretch an opposition between a type of welfare that can be defined as a unitary European and convergent welfare system, and a kind of fragmented and local welfare, defined as net local welfare systems. The axes point, therefore, to extrapolate the effect of the method (comparative policy analysis vs. Comparative geographical analysis), the continuum intersecting (semantic vs. spatial) and the main changes occurring in social policies (Europeanization vs. Decentralization/fragmentation; activation vs. welfarism; convergence vs. local autonomy, center vs. suburbs own ship of decision-making process in social policy), assuming, on one hand, a separation in terms of spatial or social development (cohesion vs. inclusion) and, on the other, the trend towards Europeanization or decentralization/fragmentation, that can be seen like general way of doing not necessarily exclusive one with the other; they are particular forms of merging and mixture that lead to the emergence of particular systems that have to be treated as a model and not as absolute and generalizable classifications. A typology in continuous evolution that becomes the integrated auspicated analytical tools that is able to accommodate different and highly heterogeneous elements for nature and origin (fig. 1). 


\title{
Europeanization Axes Spatial Continuum Geographical Comparison
}

\section{Unitarian European Welfare} Convergence

\author{
EU Integration Axes \\ Semantic Continuum \\ Policy Comparison
}

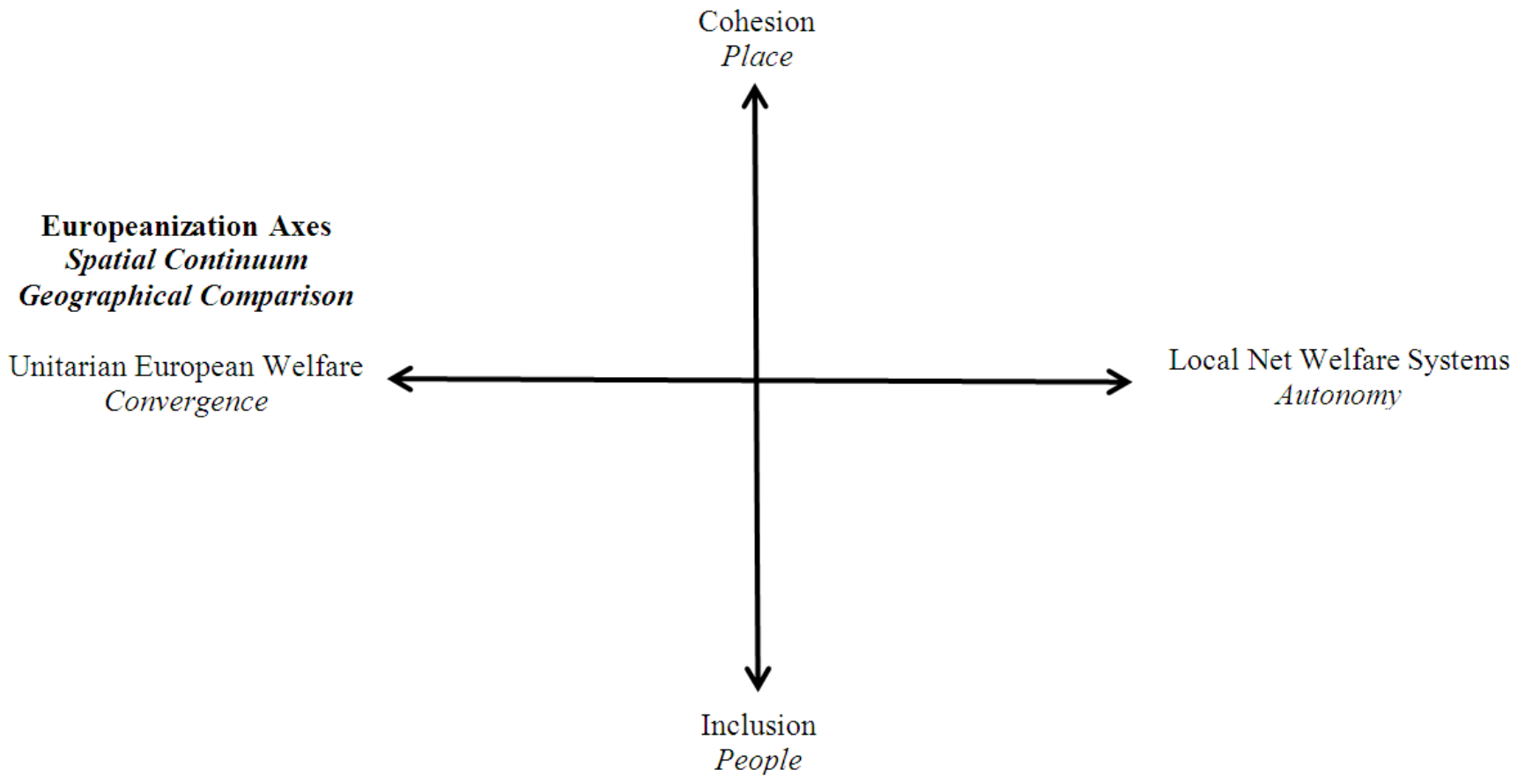

Figure 1. Typological axes originated in the model by the intersection between Europeanization and European Integration axes.

Although this typology shows in this phase all its theoretical nature, this step was also tested in the second phase of the study with the formalizations of a macro model generated on the use of social indicators at territorial level. Whereas the aims of the work, as just mentioned, is to test and complete a new model for the classification of European welfare systems by introducing new discriminant variables, following the discussed argumentations we can highlight two essential discriminant variables that correspond to the emergent axes: EU Integration and Europeanization. This can be seen as a polarization between European integration like focused on legislative dynamics and Europeanization as the mirror of procedural factors and practices concerning the integration that allows us in understanding and classified the change occurred in the investigated welfare regimes with the category of convergence and autonomy. Therefore, we will have:

- An EU integration axis based on the double-side of cohesion policies, aimed at territorial connoted development and direct to the contexts (place), and of inclusion policies, aimed at socially connoted development and addressed to the subject (people). It is the semantic continuum based on the policy comparison.

- An Europeanization axis based on double-side convergence to the European welfare and autonomy of local net welfare (the spatial continuum based on the geographical comparison).
Crossing the two axes and joint the theoretical and the empirical plans (test that will discussed in the following paragraph with the application of principal component analysis on the Eurostat and OECD indicators - to the delineation of the two components and for the intersecting of the axes - and PLS Path Modeling - for the definition of polarity in opposition) what we obtain is typological space with all the connotation for reading in it the different ways in which the welfare regimes can be divided by the introducing of these two new discriminant variables.

\section{Macro Analysis of Social Indicators: What Is the Position of Nations and Local Contexts?}

The second step of investigation is focused on the multivariate analysis (Principal Component Analysis) [38] [39] and multi-level (joint analysis of levels of variation) [40] with the formalizations of a macro model generated on the use of social indicators at territorial level.

This objective will be pursued by the creation of six indexes starting from six concepts. Two of them are the main concepts used to create the typological space and for this they were defined also discriminant variables: EU Integration - a concept of regulatory nature - and Europeanization - a concept of procedural nature. These two concepts are based on a continuum line with two 
polarizations.

The first concept, the EU Integration, is used to describe the opposition between policy data and results concerning integration, with social connotation (Social Inclusion constructed as a second level index), and data concerning policy and result that look at place development, with territorial connotation but together to direct social impact (Territorial Cohesion constructed at the same way as a second level index).

The second concept is Europeanization and it is focused on the opposition between indicators that look, on one hand, to the processes of convergence (legislative, procedural and social) and, on the other hand, to the processes of empowerment of local contexts (in expression of local autonomy). So, the polarizations used to construct the Europeanization index are Convergence Factors (Convergence index as second level index) and Expression of Autonomy (Autonomy index as second level index).

The involved analysis born in a comparative perspective in order to build synthetic indices of performance of the different contexts investigated with the intent to:

- Highlight the incisive decision-making of national or sub-national level (multiple regression models and for blocks - PLS-Path Modeling [41] - on disjointed levels before national and then regional) in the constitution of social policies in Europe;

Establish a plan for the selection of these contexts on the basis of assumed differences on the discriminant variables;

- Drawn, from these analyzes, the elements for projected into the typological obtained space generated crossing the axes either Nations (NUTS0 ${ }^{2}$ ) or Regions (NUTS2 ${ }^{3}$ ) (classification based on Rebus-PM [42] and Cluster Analysis).
The question from which we started was, starting from classic typology, what, how and how much has changed in European welfare regimes? The carried out analysis confirmed the composition of the axes identified at theoretical level supporting the hypothesis of a linear function of integration and Europeanization respect to the double highlight polarizations (fig. 2). This configuration is suitable to be taken as the dividing line between welfare systems. What follows is that the models classically understood as described by Ferrera [43] begin to mingle and merge one with the others. The distinction point of the models moves rather than on differentiating factors, that was fundamental in a time where prevailing a soft law legislation on social field, toward those of convergence, which are relevant in a time when Europe begins to establish and delineate precise and binding trajectories with respect to social growth. This is clear in the territorial component in which pressures to Europeanisation or to localization, leading to stretching two other trends, on the one hand we have a Unitarian European welfare system, that can also be called Europeanisation welfare, based on the full convergence of nations on a single and integrated model, on the other hand we have the birth of many fragmented local net-welfare systems like small centers of decisional gravitation from which start the impetus for the empowerment of the different contexts, while maintaining balance the fundamental objective of convergence in the economic and social development results achieved.

2 Nomenclature of Territorial Statistics Unit, in acronym NUTS (from the French nomenclature des unités territoriales statistique) that identifies the division of the territory of the European Union for statistical purposes (national level of aggregation).

$3 \mathrm{Cfr}$. note 2 (level of regional aggregation). 

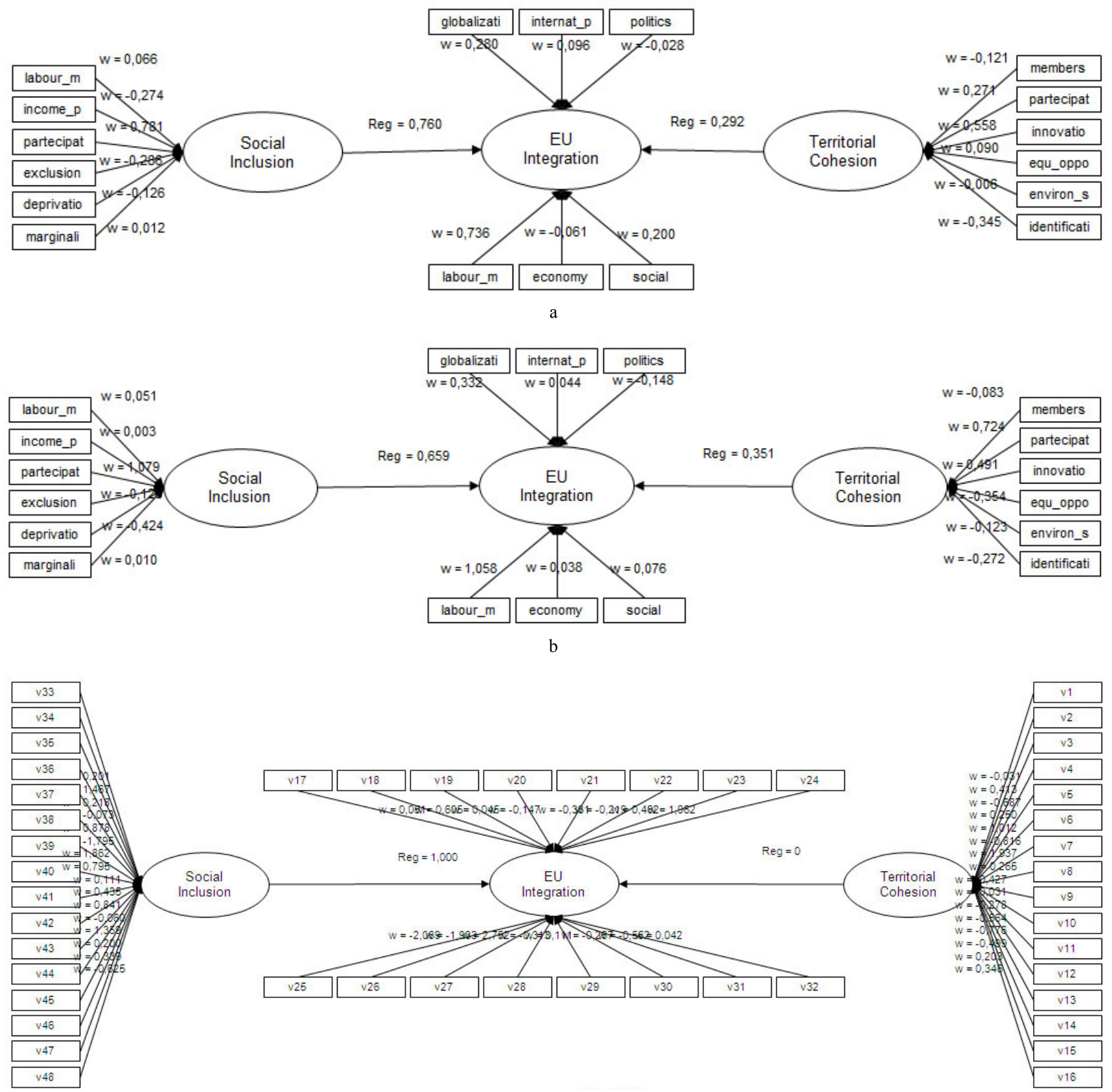

c

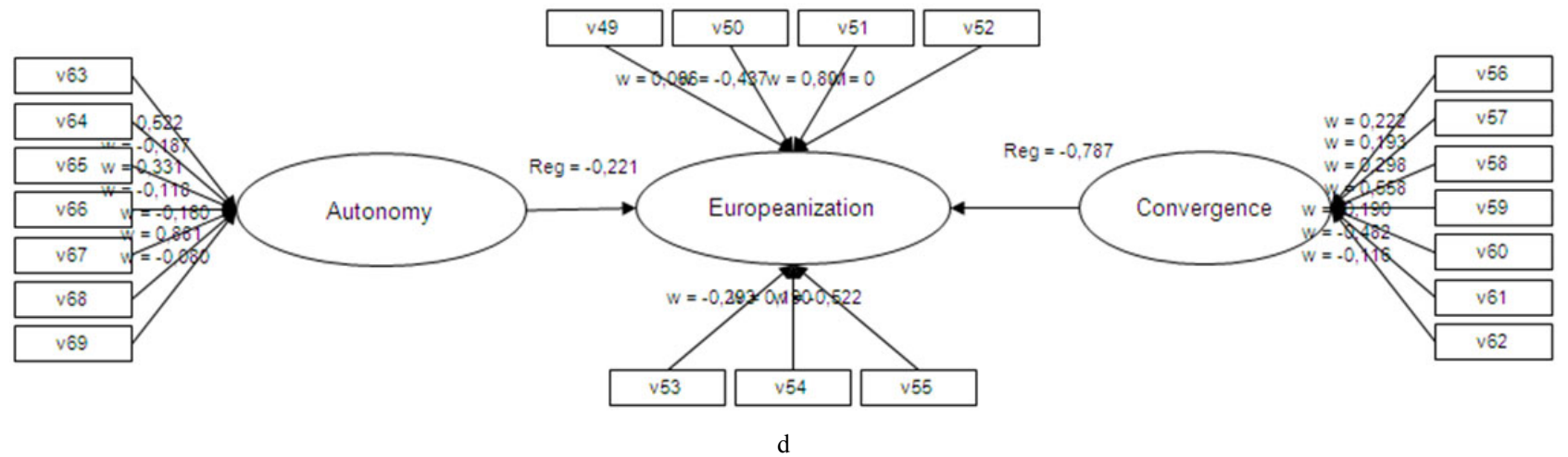

Figure 2. Partial Last Square - Path Modeling: a) regional level only on Eu integration; b) national level only on Eu Integration model restrict; c) national level only on Eu Integration full model; d) national level only on Europeanization model restrict. 
If we look at the national level, the position of nations conceiving is a mirror of a convergence driven by a legislative principle rather than a spontaneous and dynamical action of the local network. Considering, instead, the regional level, it is not difficult to see the typical territorial dimension that acts on the implementation of social policies and shows in the recovery of large areas of local autonomy. In the first case, it would seem to prevail the idea of moving towards a Unitarian European Welfare System, which, with the exception of the Scandinavian Countries already now heavily aimed at the systematic convergence, it is what was registered in Germany, France and Great Britain, which has prompted the selection of these contexts for the development of the micro model described in the next paragraph. In the second case, however, this trend is fully rejected by the emergence of Local Net Welfare Systems, different within them self and not comparable or attributable with a general model. It is this dynamics that prevail in countries such as Italy and Spain, also chosen for the micro model since returning from the crisis, or even in countries such as Greece, for the same reason, or countries of Eastern and Central Europe of recent entry into the Community with them economies and social dynamics that are still in trouble with respect to requests express by the supranational actor. Therefore, although it has been used for the macro model analysis purely quantitative techniques, in the stage of selection of the contexts for the micro analysis, the choice becomes rational and this is made to try to explain the real differences in the levels of performance achieved by specific countries and regions that reveal clearly the mix of classic welfare regimes.

In the end, looking at a jointly model that merge national and regional level (multilevel model) for understand what of these two level have most weight in the decision-making process for social policies, what is evident is that however the nations tend to convergence rather than local contexts, is in these lasts that the adaptive thrust concrete achieve, sometimes not perfectly in line with national trends. So, the major weight in act for social and in the social fields is recovered by region, and is in the convergent and divergent performance on these recorded that we can found a response to our opening question. Therefore we have to distinguish between an integration of shape and an integration of substance, of management or of address, and so because the European Union is all in line with the principle of integration, however, it is in its various nations and regions that it assumes different characters. It is emerging the subjectivity of the territories [44], their being actors in themselves and the power that the dynamics that pervade them have to engrave it on the addresses dictated by the actors at higher levels, but from which the territories can't break down because they are the basis of multilevel governance.

From the application of PCA and Cluster Analysis another think become more evident and deserves a little discussion first of presenting the projection of group and nations in the typological space: the consolidation of the difference between group both from a legislative and regulatory plan (European integration) then from a procedural point of view (the Europeanization process). These emerging difference can be read as different way of convergence sometime driven by the national level (fig. 3, such as in the case of Germany, Sweden, France), where it don't pass great difference between the national average and the averages of the regions in the nation, and sometimes driven by the local level (fig. 4, such as in the case of Italy, Spain, Greece and Eastern European Country) where exists a great difference and dispersion between the national and the regionals average. 


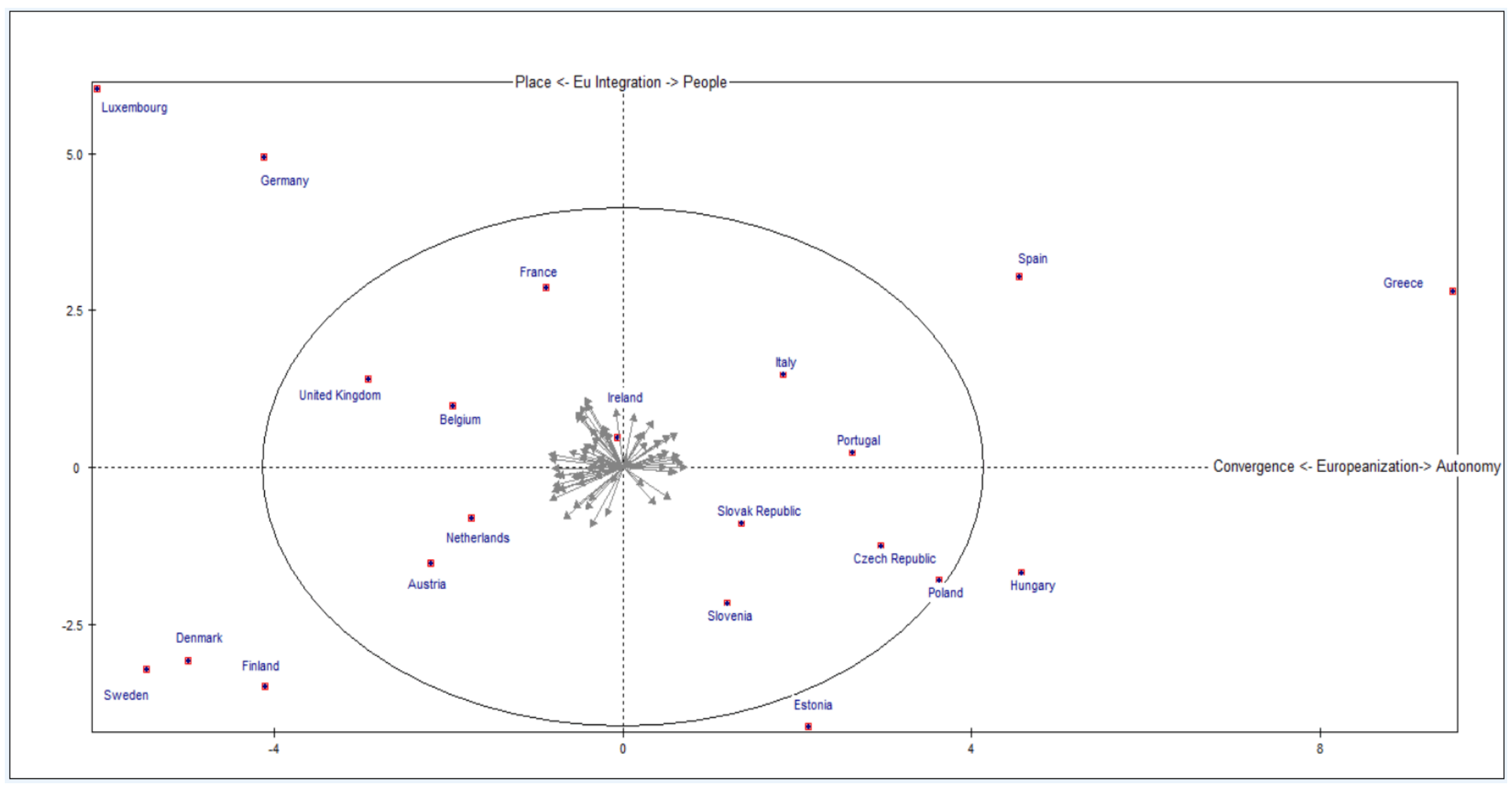




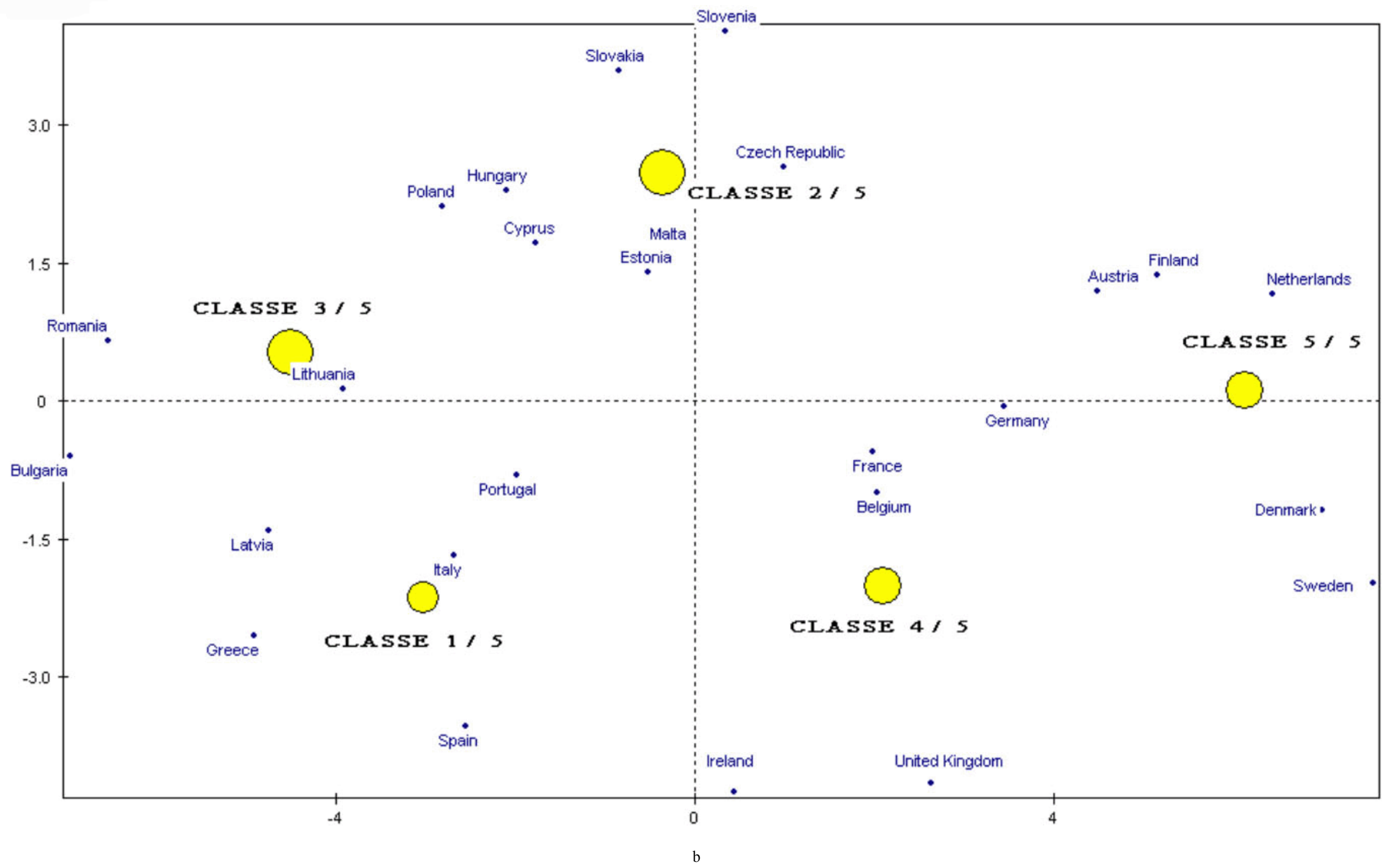

Figure 3. Principal Component Analysis on European Nation - a) on Oecd dataset - 21 nations; b) on Eusilc dataset - 27 nations). 


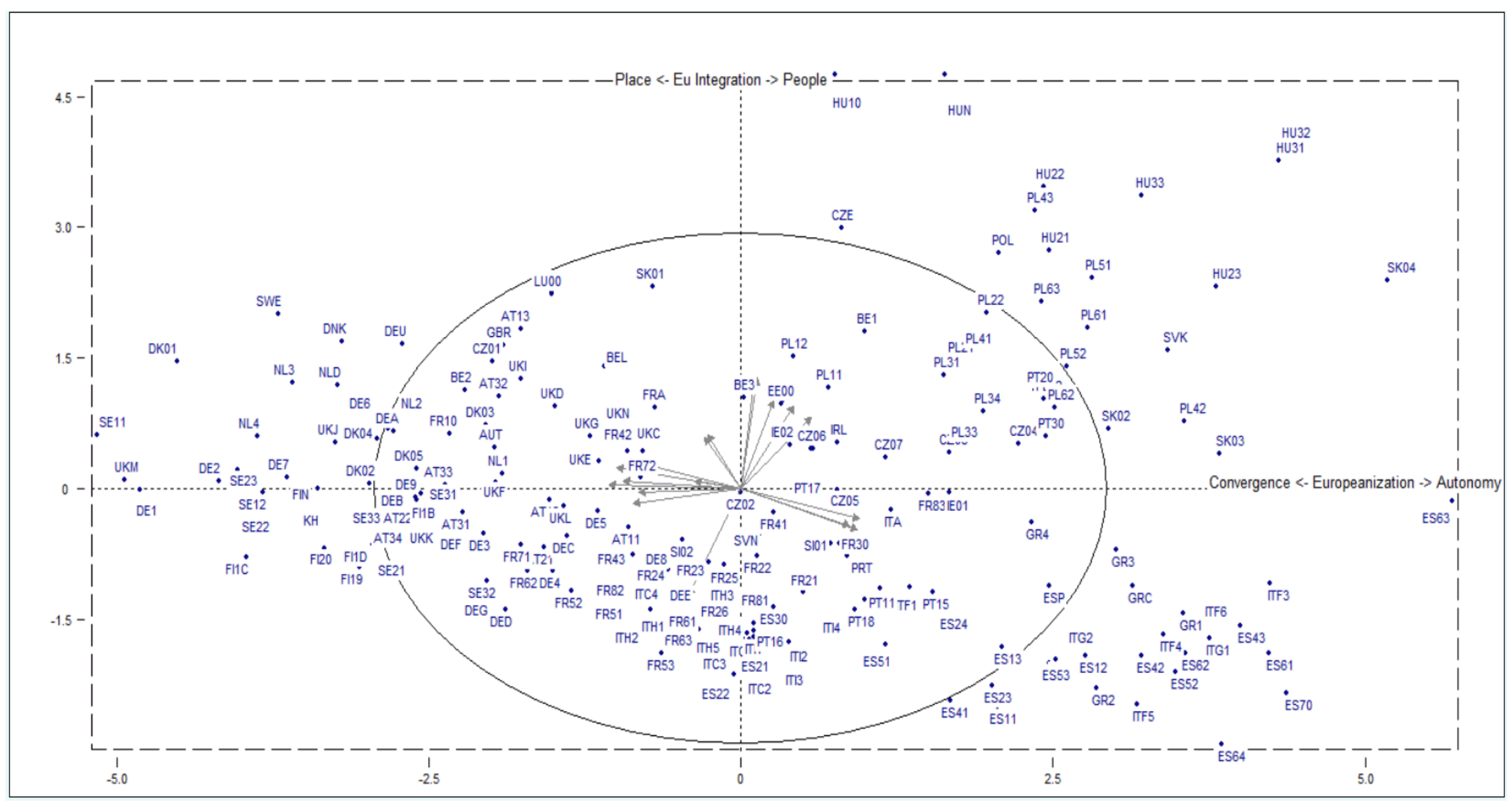

Figure 4. Principal Component Analysis on European Region (Nut2 level)

The main result obtained, in the aim of the integration of the results of each step of analysis in the general model of classification, is the provision of nations and regions with respect to the EU Integration and Europeanization index jointly to the emersion of the resulting groups (clusters) that this entails, which were projected as features and attributes within the quadrants emerged from the intersection of the axes. This completes the space of attributes and allows us in delineated four distinct modes of integration. 


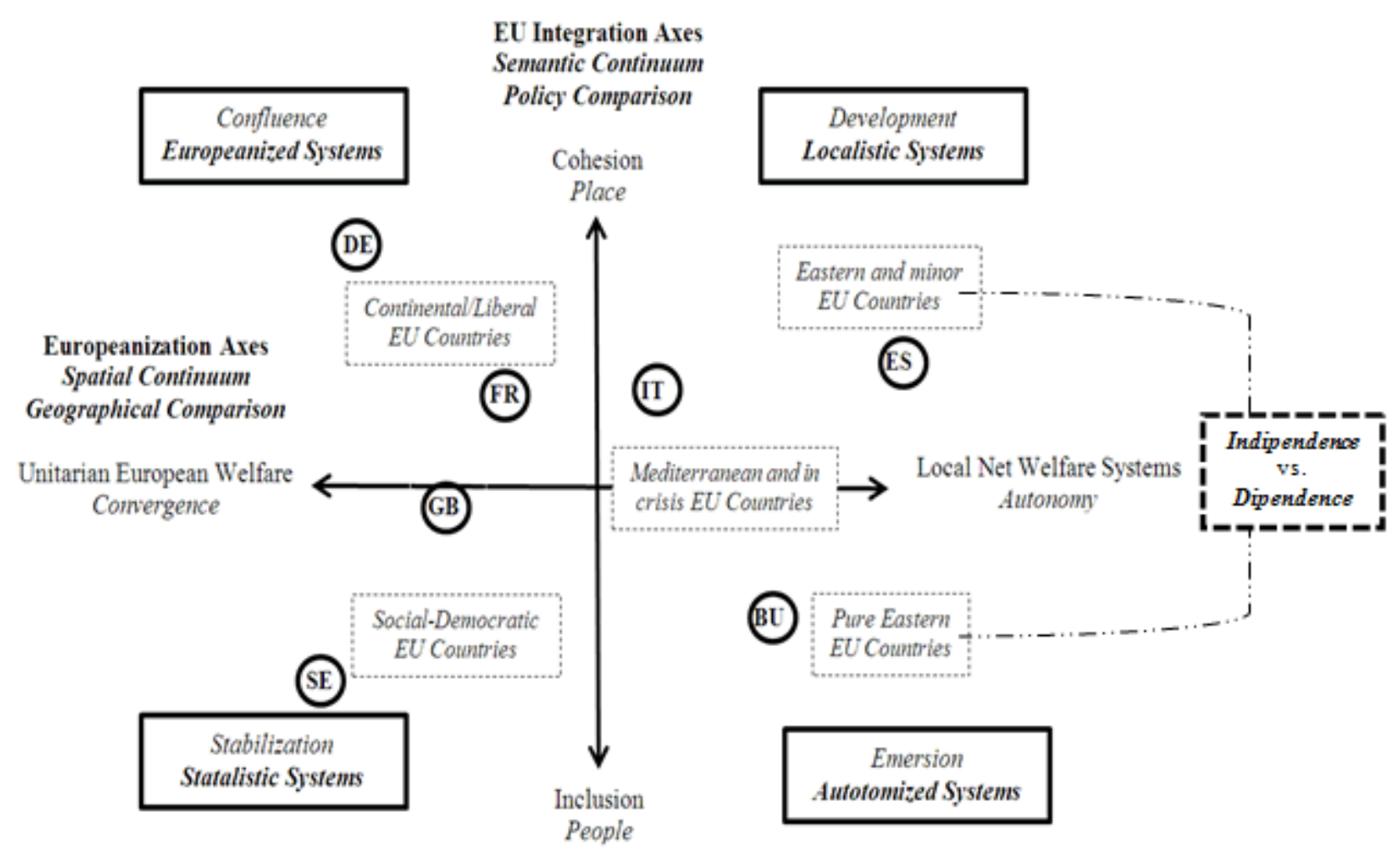

Figure 5. Projection of nations and group of nations in the typological space are presented in Figure 1.

The modality of integration for each quadrants and the arrangement of the nation-groups are outlined and assume differential characteristics. The nation's groups take over the geo-political connotation and lead to the definition of specific way of reading the emerging dimensions. Inclusion and cohesion, for example, take on the meaning of breathlessness in addressing social development, on the one hand, and territorial development, on the other hand, when referring to more poor and undeveloped countries. In contrast, these same dimensions take the connotation of human development and competitiveness when they are associated with countries with more stable and developed economies. It is interesting to see, at this regard, as the Eastern and minor European countries prove clearly split into two groups that recover historical and cultural heritage and come to form a new continuum that cross quadrants: independence vs. dependence, revenge of their specific against cultural orbiting and approval. We are talking about countries like Ireland, Czech Republic, Slovakia, Malta, Cyprus and Slovenia, which, although near to powerful centers of influence (e.g. UK to Ireland or Russia for the Czech Republic that is the most European nations of the boundary Russian countries), however, have asserted their uniqueness and promoted their specificity more territorial then social (thinking about tourism competitiveness for Malta and Cyprus for example). The quadrant in which they occur is born from a cross between a marked tendency to focus on policies of territorial cohesion and a strategy based on the recovery of spaces of autonomy that leaving clear glimpse the membership to the local net welfare systems. The strategy of integration that characterizes this quadrant is defined Development as a strategy for growth in new forms of competitiveness. Different is the group of Pure Eastern European Countries (Latvia, Bulgaria, Romania, Hungary, Estonia, Lithuania and Poland) under the aegis of the Russian that characterized the levels of development of these countries. Distant, socially and economically, from the European model, these countries are currently working to reinvent strategy of recovery of social gap strongly felt that puts them in trouble with respect to the expressed needed of development also on territorial and economic side, on which, however, in differential way in each local contexts, appear to be climbing rapidly. This explains the position in the quadrant that crosses stretch out towards social inclusion policies in conjunction with recovery of spaces of autonomy as well as in a local net welfare. Here the integration strategies used is the one defined as Emergence of contextual specificity and states of backwardness which involve the need for a strong recovery of the social gap still persists, precisely according to the cultural heritage which acts with its strong influence. Not surprisingly, however, find in a rather cohesive and close way the Mediterranean countries affected by crisis (Greece, Spain, Italy and Portugal), and then united by a marked slowdown of the system that leads them to decline in the levels of performance and ranking of development. Those countries that characterize a specific quadrant, are placed on the average with respect to the axis of integration, so moving markedly on either side of cohesion or of inclusion, while on the Europeanization axes they stretch, although not in an uniform way (which will be explained in the analysis of the cases of Milan and Naples) towards autonomy and differentiation of local regimes, also in this case identifiable with the local net welfare systems. At the level of social performance recorded by the analyzed 
indicators, these countries are in sharp decline, which, rather than bringing these countries to focus on integration strategies aimed at developing competitiveness or on emerging of some specificity, drives them to become the emblem of the consequences of the economic crisis and of its impact on the weakening of the social protection system, moving to a decisive turning these countries that is the need of recovery both economic as social gaps. Italy and Spain, as countries identified for the investigation micro, lead one on the slope of the Emergence intended as a recovery of social problems greatly inflated by the economic crisis (Italy), and the other on the side of Development, understood as focusing on competitiveness, enhancing on the empowerment of territory in a scenario in which was the social crisis that has led to the emergence of economic-contextual contradictions (Spain). There is, then, the group of Social-Democratic and pro-Scandinavian Countries (Austria, Finland, Denmark, Sweden, Luxembourg and the Netherlands) who are currently living a form of systemic Stabilization with respect to the welfare that was made of upward trend over time in social performance levels and a corresponding possibility of joint growth both from the point of view of social than from the point of view of competitiveness and territorial. The quadrant in which are inserted is establishing a strong integrative strategy defined Stabilization. This strategy reflects nothing more than the achievement of a welfare regime strongly characterized by peculiarities and distinctive features, which don't have to recover backwardness but that pushes with decision towards the reinforcement of its specificity, attracting to whether nations orbiting in decisive mechanisms of convergence at the European welfare state which strongly advocates the supranational actor (the United Kingdom is to be drawn). Finally, there is the group of Continental and Liberal European Countries (Belgium, France, Germany and the UK) that point to a tight systemic confluence, not to the functional Scandinavian model but toward a model with all European specificity, often identified with what has been called the European Social Model [45] and that in reality the last few years has shown tends to its utopian character when we try to decline it on vastly different contexts for the contradiction in term that see it focused on principles of differential revaluation, subsidiarity and open method of coordination. The quadrant in which these nations fall is formed from the intersection of integration that is based on clear development strategies in the sense of territorial cohesion, provision of services and increase competitiveness, as well as the dynamics of convergence understood in the sense of integrative strategy of Confluence toward regulatory dynamic and procedural practices that bring directly to the creation of a Unitarian European Welfare System. If Germany and France are linked without doubt to this quadrant, the United Kingdom is released little by this group of countries to which it belongs since to stretch out with the countries in the side of Stabilization.

\section{Micro-model on Local Contexts and Projects Analysis: Spaces of Autonomy, Legislative inconsistency and Social Networks Such as Relational and Decision Spaces}

The last two steps lead to the reflection over the macro level on a micro-model of analysis focused on the study of specific cases, passing by the context analysis through social indicators to the study of the projects implemented in local contexts and networks of actors who work there. The perspective adopted in this phase is that of Europeanization and of the different ways in which it can be presented [46], including the possibility of convergence or inconsistency legislation that this perspective generate in each contexts. It means carry out the comparison within the nations (international comparison) and within local contexts (intra-national comparison) through the analysis of specific realizations: the projects of social inclusion and territorial cohesion. At the moment, in fact, it was made five international (Italy, France, Spain, Germany and the UK) and nine intra-national comparisons (Milan and Naples, Rouen, Barcelona and Vigo, Berlin and Munich, London and Liverpool). The principal aim was to complete of feature and attribute all quadrants of the emerging typology and to understand if it is in the micro dynamics that can actually be traced the dimensions of decision-making and of address of the different welfare systems.

Taking Graziano [47], and then using the strategy of comparative policy analysis, we selected two projects for two different areas of policy, one relating to territorial cohesion (urban regeneration projects with expected social impact), and the other on social inclusion (projects aimed at integrating young people unemployed), as these represent the two extremes of EU integration axis. For each project and context, have been developed five interviews administered to developers, financiers, planners, operators and technicians involved in the implementation and development of the considered projects. With the interviews was intended to: contextualize the projects; undertake an analysis of the implementation and impact based on the perception of witnesses; reach the reconstruction of networks of actors who have actually done it and decided in the local context investigated. The aim was to determine the effects of Europeanization and localization on the actual local relational configurations and on the spaces of legislative autonomy and decision-making in the context that the actors are able to recover. Therefore, if the approach for variables used in the analysis of social indicators, pointed to the emergence of the differences for the selection of cases and their classification within the different dimensions of integration emerged using cases/countries as places for the measurement, the approach for cases that is proposed in this third step has been used to recognize the complexity of the unique and unrepeatable events and investigate developments. However, the comparison between policy 
showed that the differences attributable to the individual sphere of policy is not considered a direct impact on the structuring of the different welfare systems developed, while significantly affect the manner in which it is perceived and implemented the integration by the different contexts analyzed. Therefore, much more interesting is the geographic comparison intra and international that leaves out the weight of the territorial and of potential decision expressed by the lower levels of governance.

Leaving aside here the specificity of each context and for each project, what is interesting to point out are the differences emerging, from one hand, respect to regulatory constraints, perception of incongruity, degree of autonomy, impact and implementation procedures, and, on the other hand, respect to the conformation of the networks, dynamic of decision-making, conflict and mediation.

For Graziano [48], the processes of convergence or empowerment of the local level of government, compared to Europe, stem from different ways to implement and translate the regulations at different levels of governance, also generating inconsistencies in the application of legislation. The existence of this space and the perception of incongruity that have the actors involved in the implementation of policy in the projects can be functional to the structuring of spaces of action and autonomous decision-making with respect to the system of general legislative constraints. To detect this connection, at the witnesses were asked questions about the normative question (type of regulatory bound; perception of the discrepancy in the reception and application of European regulations on the local level; classification of the type of discrepancy - facilitating or retardant in the process of European integration?; consequences with respect to a possible adaptation of policy) and the detection of the degree of perceived autonomy (detected in the form of scales from 0 to 10 times to investigate the perception with respect to the recovery of autonomy space by the actors involved in planning, expense management, implementation and strategic decisions to achieve goals). The basic hypothesis is that the increase in perceived autonomy in each phase is directly related to the perception of incongruity application of the relevant legislation and the binding nature that this assumed.

Taking into account the trend in average measured against the degree of perceived autonomy in strategic phases described, the indication of the nature of the bond and the perception inconsistency it is possible to compare the different contexts involved in the analysis. What has been found in general is that the only difference found for different areas of policy are in the amount of funds associated with the European cohesion policy, which is greater than the inclusion in all contexts, obviously it makes the legislation about these more binding and the perceived degree of autonomy with respect to these projects, in general, for all contexts, lower than those of inclusion.

Turning to differences for geographical comparison and starting from Italy the level of autonomy in the different phases in Milan and Naples, as regards the intra-national comparison, is rather high and is associated with a regulatory constraint that goes from strong to coordinative bound for the different levels of governance involved and a perceived inconsistency in the application and translation of rules but differential for context. If the inconsistency in Milan more than free spaces of autonomy leads to slowdowns and delays in the ability to align to the scenario of the Unitarian European welfare System, in Naples, the incongruity is perceived as an advantage in the ability to adopt alternative strategies without departing from the achievement of common goals.

In Germany, precisely starting from Berlin, however, the level of perceived autonomy is good and the regulatory constraint is moderate. Here it is not recognized in the mindset of the administration the opportunity to voluntarily exercise the process of incongruity. The prospected scenario is a full convergence in every regulatory and practical aspect, because it is conceived the successful as a function of regulatory adaptation. This arrangement has obvious implications in terms of impact, so if the best results, both on recipients then on territory, are imputable to Berlin - where the implementation is conceived as procedural standardization as a function of convergence and with the overarching goal to make bureaucratic the whole process, approved and loyal to a standardized application - good level of impacts are recorded in Milan - where the implementation takes greater account of the concerns of concordance with the needs identified locally with respect to the scanned application procedures and with the overarching goal to made network locally - and decidedly more limited and relative impacts are achieved in Naples - which implements differential implementation strategies applied with due regard, however, the objectives set and the overarching goal to capitalize on decision-making, power and economic resources. The processes of integration and Europeanization are outlined in the Italian scenario still far from full convergence and structural capacity to absorb regulatory, tied to a vision of the differential development of social policy on a territorial basis. Always returning to the comparison intra-national for Germany, Munich backs in high levels of perceived autonomy, together with regulatory constraints and coordinative management and absolute absence of perception of incongruity. As for Berlin, also in this context the impacts are very good and the implementation assumes standardized features aimed at obtaining the best possible results. The processes of integration and Europeanization are outlined in the German scenario aimed to the convergence as fully absorbing European addresses.

Very similar to Germany with respect to the characteristics investigated is the United Kingdom with London and Liverpool, two local contexts that are almost completely interchangeable with the characteristics observed, showing a marked inconsistency of intra-national comparison. Autonomy levels recorded are extremely high, the regulatory constraint are made of coordinative bound, the inconsistency, despite the large degree of autonomy, is not 
perceived and the overarching goal is the respect of local dimension which is totally in line and ready to implement the objectives and procedures dictated by the supranational actor. Becomes essential to reduce slowdown factors, which can engage implementations heavily bureaucratized, promoting more local initiative and less Europe, especially with respect to the design and the recovery of funds for local development. The resulting impacts appear to be limits to the territory that is compared to the recipients of the interventions investigated. The processes of integration and Europeanization are outlined in the Anglo-Saxon scenario as aimed at the convergence fully absorbing European addresses but claiming its own specific implementation of local decision-making and autonomy.

Different the French case, which is currently represented exclusively by the context of Rouen as interviews of Paris are in the process of development. In this context, the observed levels of autonomy are fairly good, and the relevant legislation have strong bound and the inconsistency rather than manifest it in its legislation characterization, is shown with procedural connotation as obstacles encountered of administrative and bureaucratic nature in the implementation of standardized procedures in a context that would require flexible application. This peculiarity is due to the fact that France have as a cross-cutting objective of the consolidation of the partnership networks, able to listen and understand deeply the territory following its needs, but without detaching the aim of convergence. The impacts achieved therefore are good but suffer in the implementation phase, of breathlessness in adaptation of legislation for specific local needs and context recall, not fully conjugated with the European impositions. The processes of integration and Europeanization are outlined in the French scenario as aimed at regulatory convergence slowed down from the implementation procedures and from the increased concern for the local.

Finally, in Spain, both in Barcelona then in Vigo, the situation register not expected a significant gap in terms of intra-national comparison. Here is recording the lowest degree of perceived autonomy, stringent regulatory constraints, detected perception of inconsistency legislation on differential basis for the different levels of governance involved, detected mainly in the translations of local autonomy than the national context, and yet not seen as facilitating factor. The unifying goal is the willingness of the creation of networks of communication between the various levels of government that may, in fact, address the issue of applying the differential between different levels. This leads to positive impacts on average, with a tendency to comply with the objectives set by the plaintiff European, rather than to procedures, but showing an inevitable trouble adapting regulatory explained in the actual lack of coordination between different levels of government involved. The processes of integration and Europeanization that are outlined in the Spanish scenario, like the Italian one, are still far from full convergence and structural capacity to absorb regulatory, tied to a vision of development differential on a territorial basis.

The last step of analysis involved the networks analysis arrangements as relational and power configurations that can be more or less conflicting. Policy network made up of actors, as well as public then private that possess resource qualitatively and quantitatively different, and operating within a defined space of policy. It can be understood in the sense of variable configurations of links between individual and collective actors [49] [50] but also in the sense of poles of attraction focusing on socially perceived problems and capable of attracting variously qualified and interested actors [51]. The application of network analysis is to understand whether it is in the micro dynamics that can be traced the dimensions of decision-making and address for the different welfare systems by giving to the structure or to the actors of the network the key role of the dynamics of address. In the original study Therefore It was taken into account socio-centered network representative of the investigated projects (respectively one of inclusion and one of cohesion for each local context). In them the bonds were weighed on the intensity of the relationship understood as multiplicity (multiplexity) that means the possibility that within the bond highlighted steps more than one type of bond (professional, friendship, parental, institutional). After, we put in evidence the conflicting and the mediation actors (economic for materials resource; emotional and personal; decision-making relating to the informal power), to figure out which position is confined within the network for these actors and how this can be useful for the decision-making purposes. By analyzing the levels of openness of the network, its density and cohesion, are highlighted three spheres of strategic importance on which actors operate: the positional (official and institutional), reputational (subjective) and decision-making plan 4.

Starting from Italy, in Milan there is the emergence of extended network, dynamic, inclusive, loose knit, arranged to contain and discuss the external and internal conflicts within the constituted relational space, equipped with many points of mediation, based on integration, dynamism, openness, horizontal structure, division by spheres of influence and composed of multiple actors for constituted areas, many stakeholders next to implementers. The tendency is to flow into the local net welfare system whose goal is the integration of the EU, but whose strategies go to inextricably bind to territorial specificities and to the network of actors exploiting the spaces of incongruity in the creation of a regional strategy fully adapted to the Milan context. The structure of the detected network, based on a core of primary relationships and branching of these secondary relationships, suggests that decisions are created and placed on the network right from the center, also identified as the decision-making sphere, which is to be configured in such a way, also as a center of power. A capacity of centralization and accumulation of functional

\footnotetext{
${ }^{4}$ To the witnesses were asked to indicate the actors involved compared to the three spheres of matter and their interconnections, indicating the nature of the link between subjects.
} 
communication, information and resources typical of the issue network bring this context to stretch out together both

towards social inclusion policies that territorial cohesion.

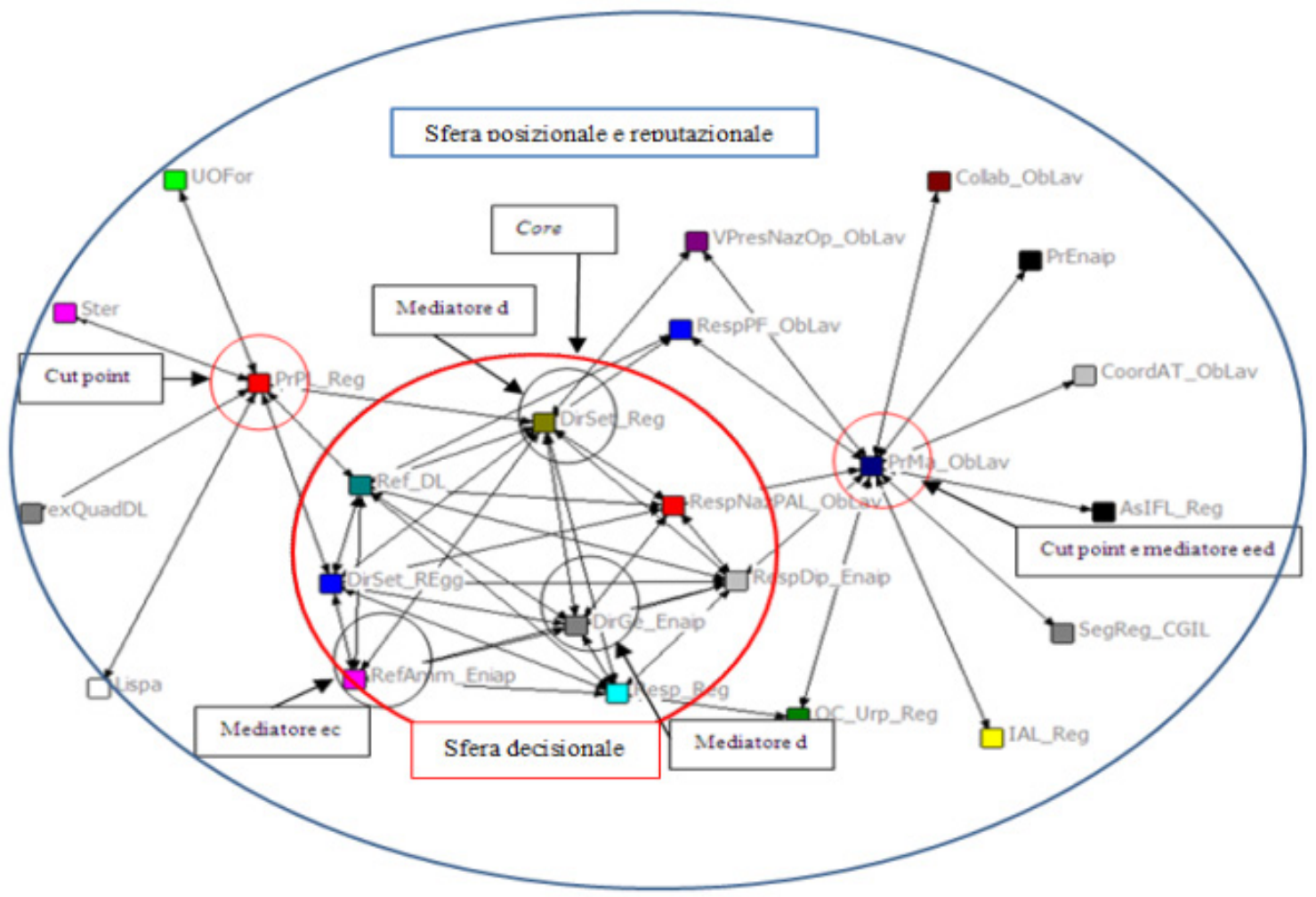

Figure 6. Network for social inclusion Milan

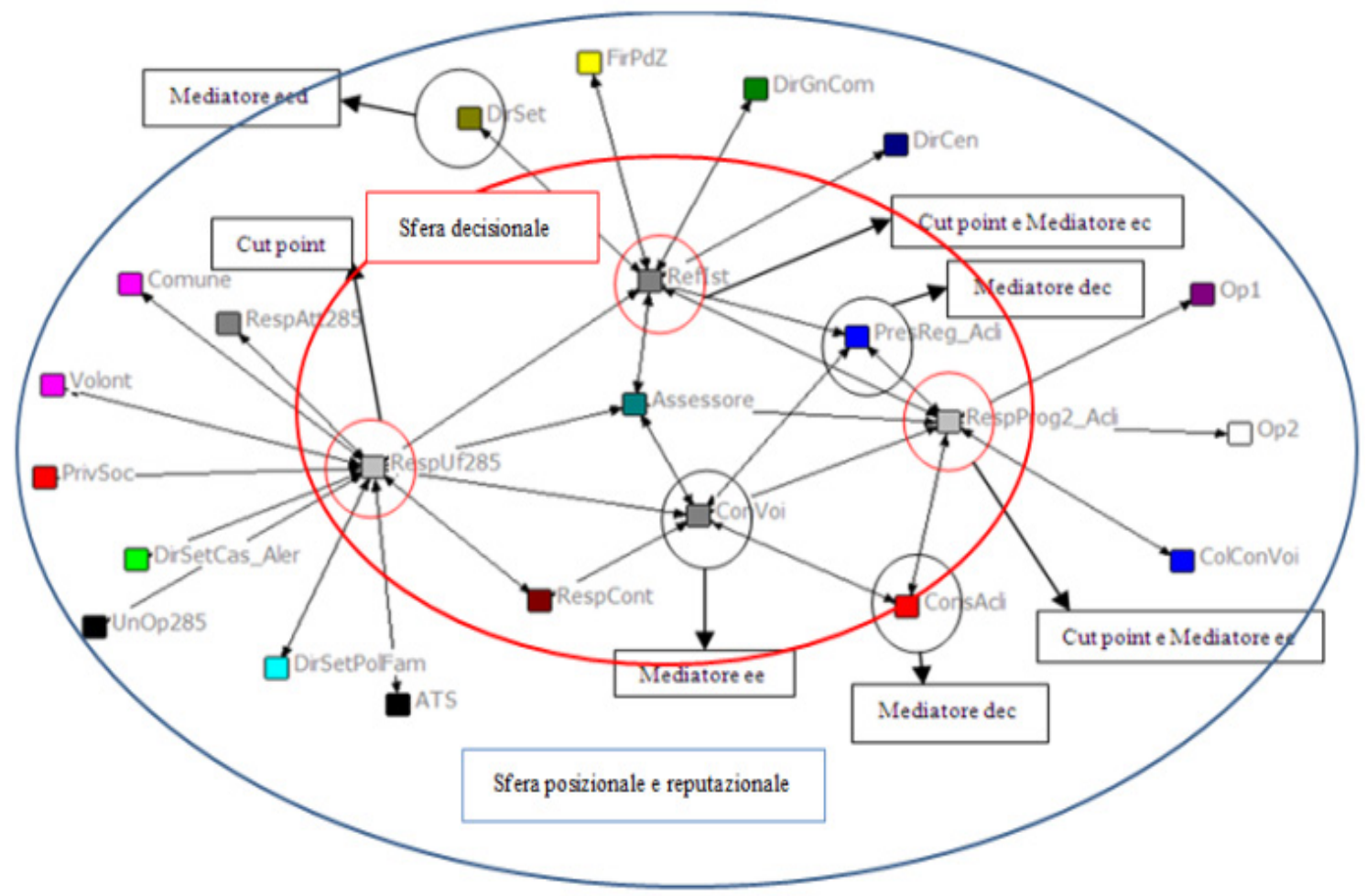

Figure 7. Network for territorial cohesion Milan 
In Naples, instead, they emerge lobbyists network, tight and focused, made of multiple bonds, strong and tight knit, within which the conflict is included in the net and made a sharer in the sharing of information, decision-making, strategic and operating the power ability, providing, in contrast, also figures devoted to mediation. Based on exclusivity, strong powers, cross- memberships in most areas of policy and with decision-making structures are at the top rather than horizontal connection. In Naples the focus are on policies of inclusion in a system of local net welfare whose aim is the European integration, but with strategies inextricably bind to territorial specificities and the commingling of interests that are present on the context, so the network of these actors who are able to move using either the spaces of inconsistency legislation is the possibility of emergence and conflict management by incorporating internally and causing it to become an active part of the decision-making process and the formation of the power of the local management of the choices on the welfare system. The actors involved are implementers but also local powers, policy and institutional actors, with the absence of external stakeholders.

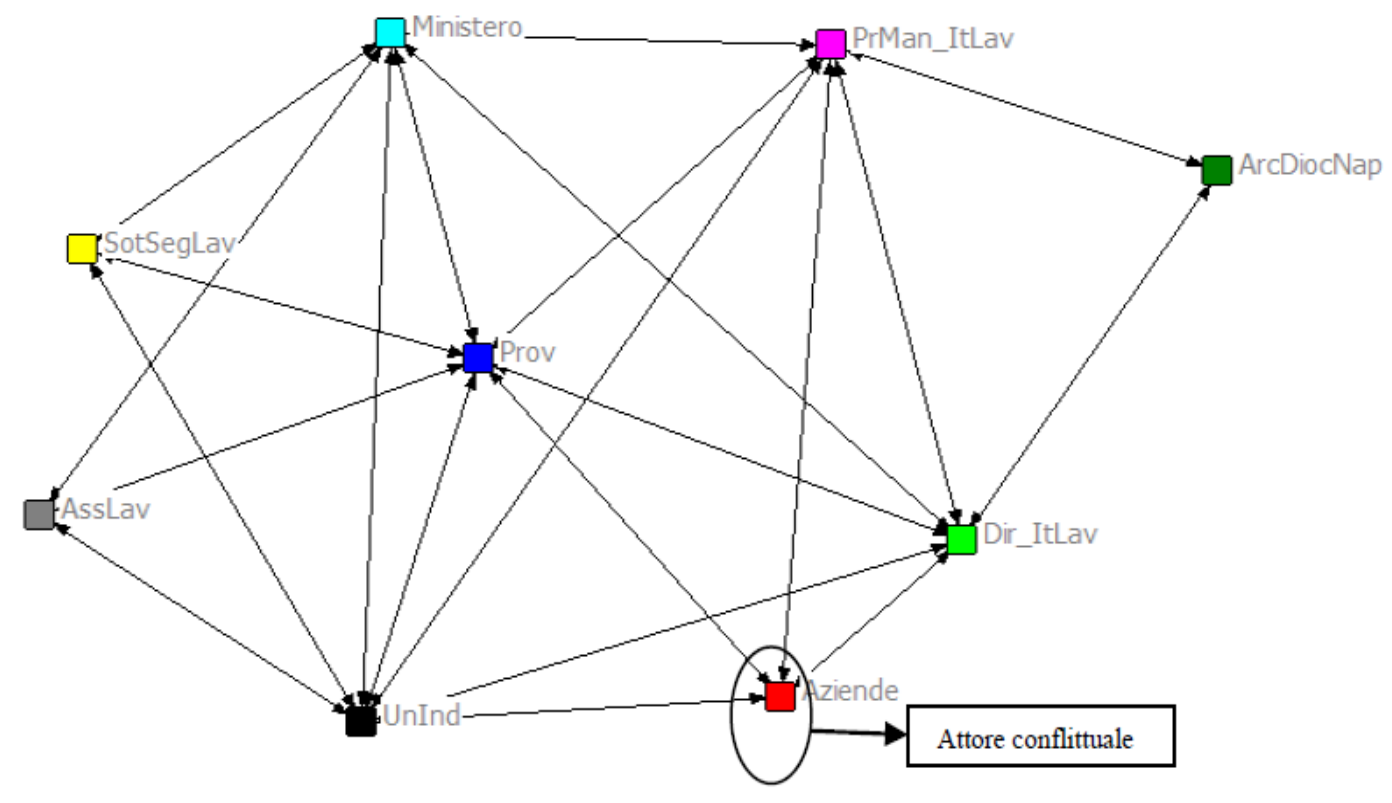

Figure 8. Network of social inclusion Naples

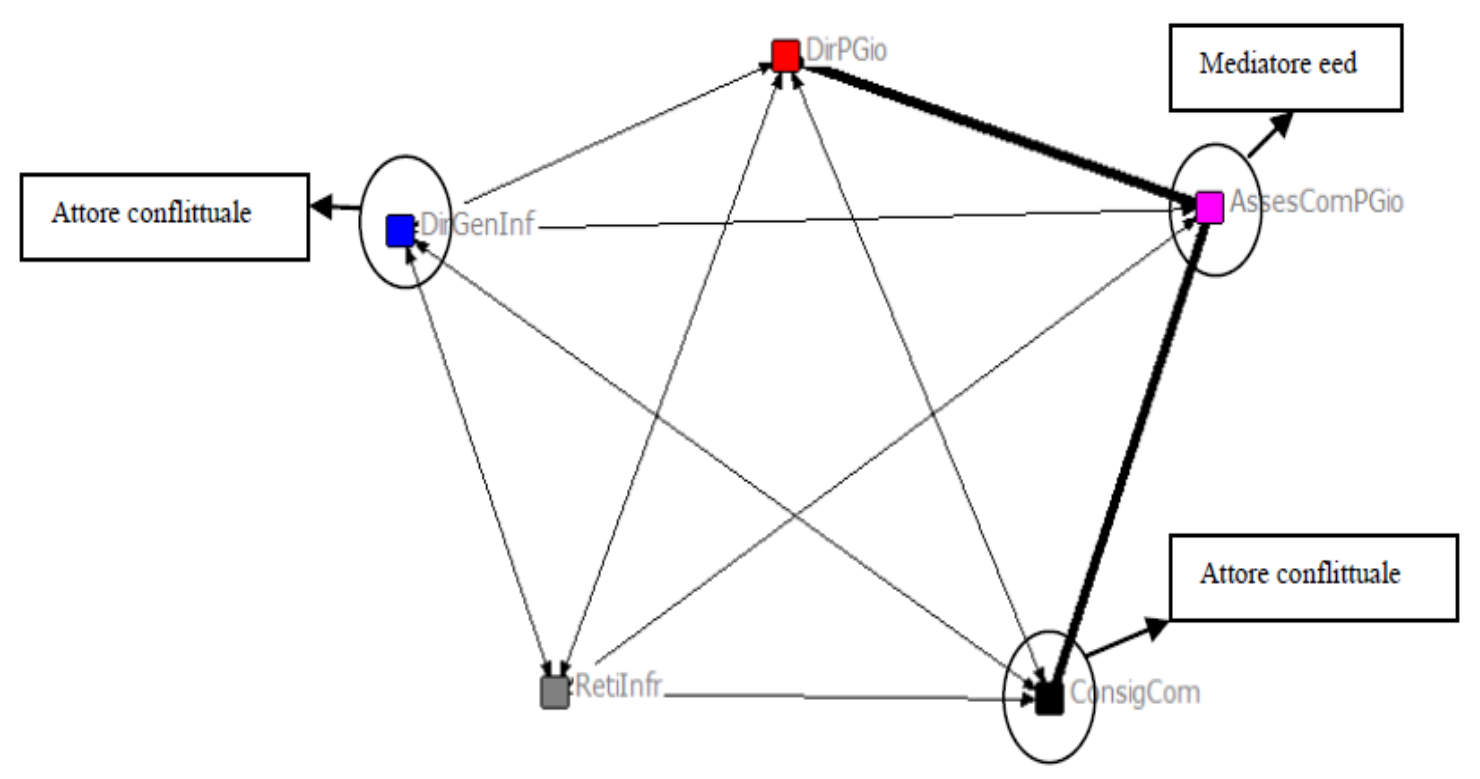

Figure 9. Network of territorial cohesion Naples

In Berlin there are restricted network, cohesive and structured, whose actors are part of a single institution who is the general association of the third sector which is responsible operationally of the implementation of the projects. A character, 
this, badge does not require having to open outside (Milan) or to include strong interests in the network formed (Naples). A network with tight knit, thick and made of multiple and strong bonds, structured to contain the conflict, even when it is not revealed, providing always the presence of mediators. Stability, exclusivity, closing and synergy are the benefits of this network that leads to the structuring of real policy community, in which there is an interest in an exchange not merely material but based on a more extensive sharing of the same value system, which see the success of the project as a function of regulatory adaptation. The actors involved are all implementers and operators. The tendency is towards a regulatory, institutional and community convergence and toward a Unitarian European Welfare System structure more focused on the territorial impacts and therefore more dedicated to give space to cohesion policies.

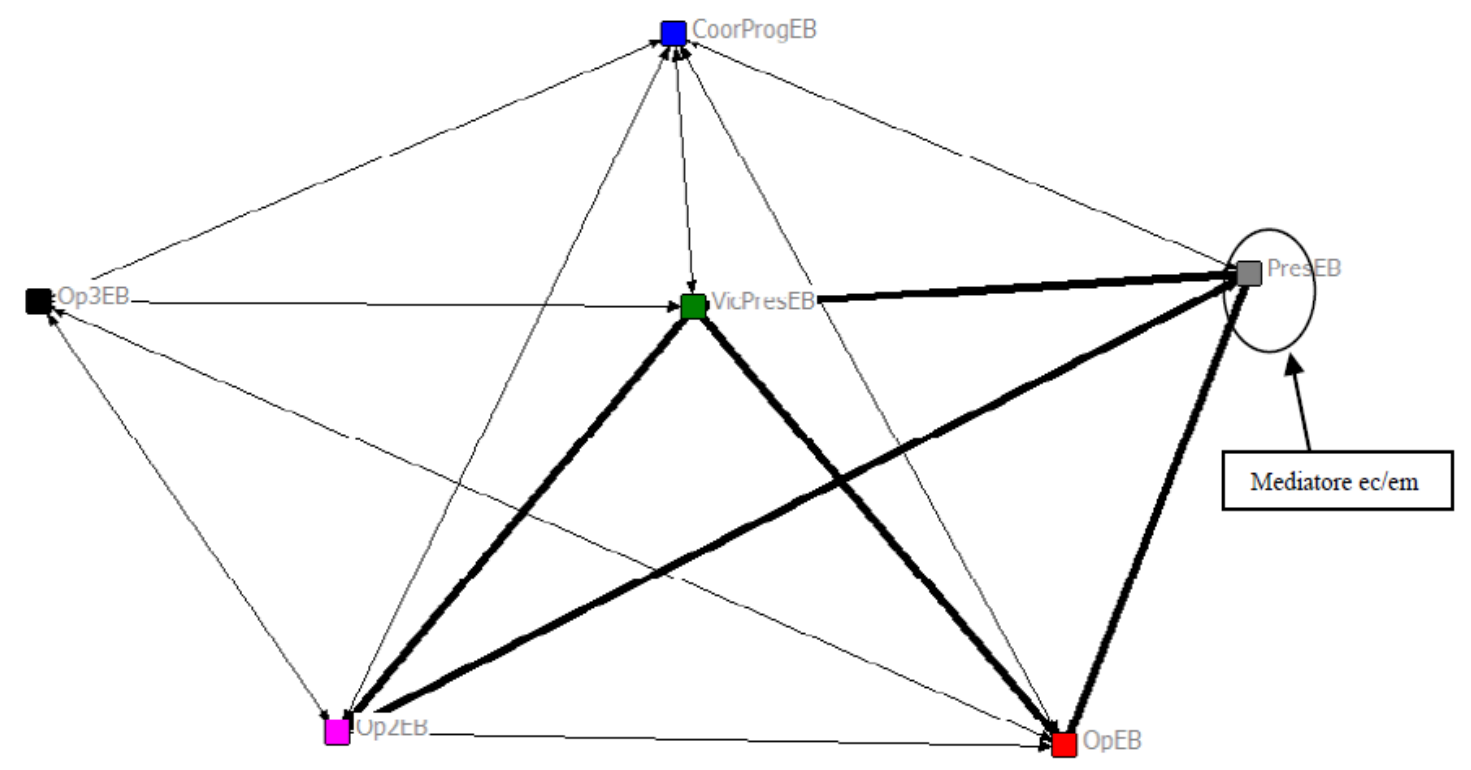

Figure 10. Network of social inclusion Berlin

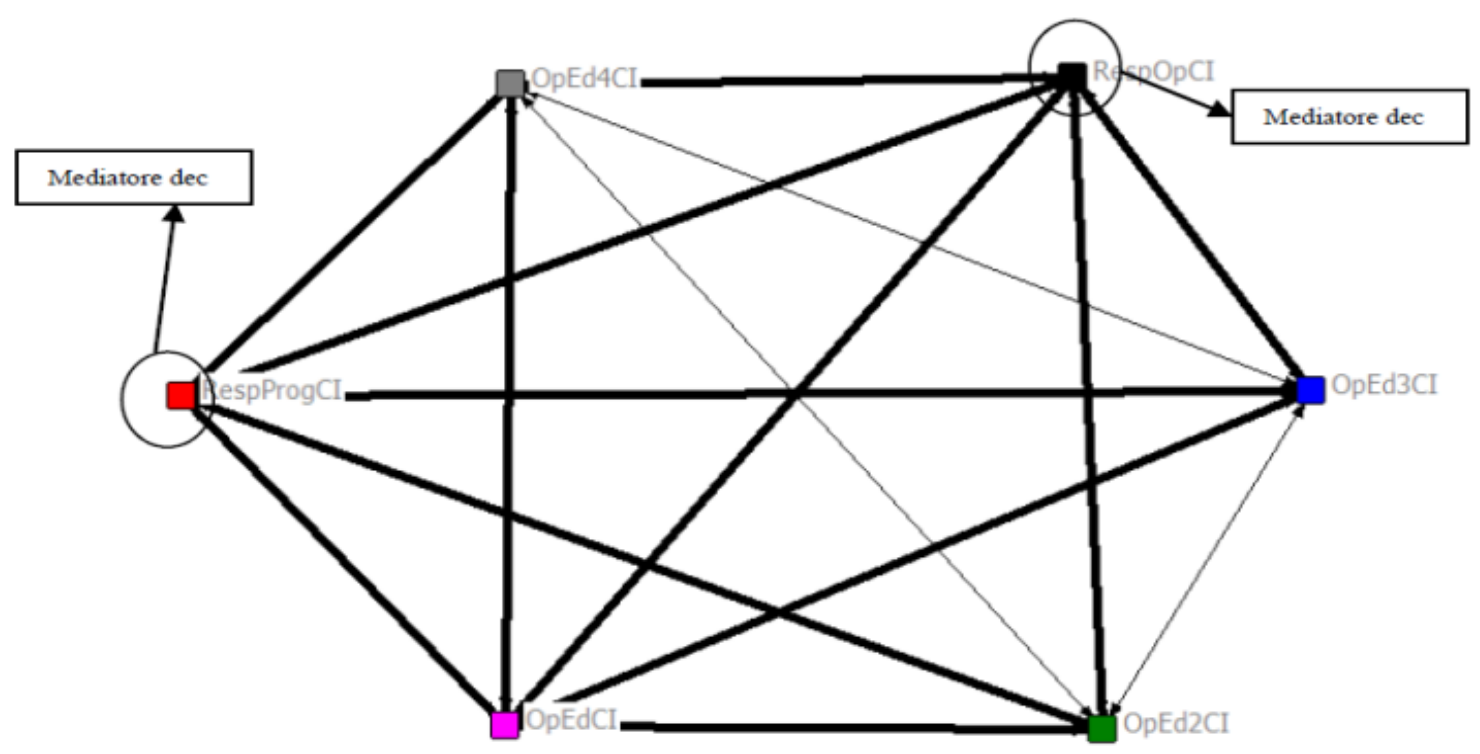

Figure 11. Network of territorial cohesion Berlin

In Munich the networks are highly interconnected, tight, cohesive, tight knit, dense, in which the conflict is not detected but at the same time it is expected at least one mediator. Closure, little inclusiveness, stability and internal synergy leading to the typical structure of the policy community in which they are involved always the same actors for the three spheres considered (decision-making, reputational and positional) that are dealers and implementers come from an unique association with the absence of external stakeholders, not recognizing, as in Berlin, the need to be open to the territory or include strong powers. The relaxed, marked and regulated atmosphere (stringent regulatory constraints) makes mechanics the decision and implementation of social policies in local contexts, just as it was standardized protocols, in which prevails the tendency to converge to Unitarian European Welfare System and the reaching out territorial cohesion policies. 


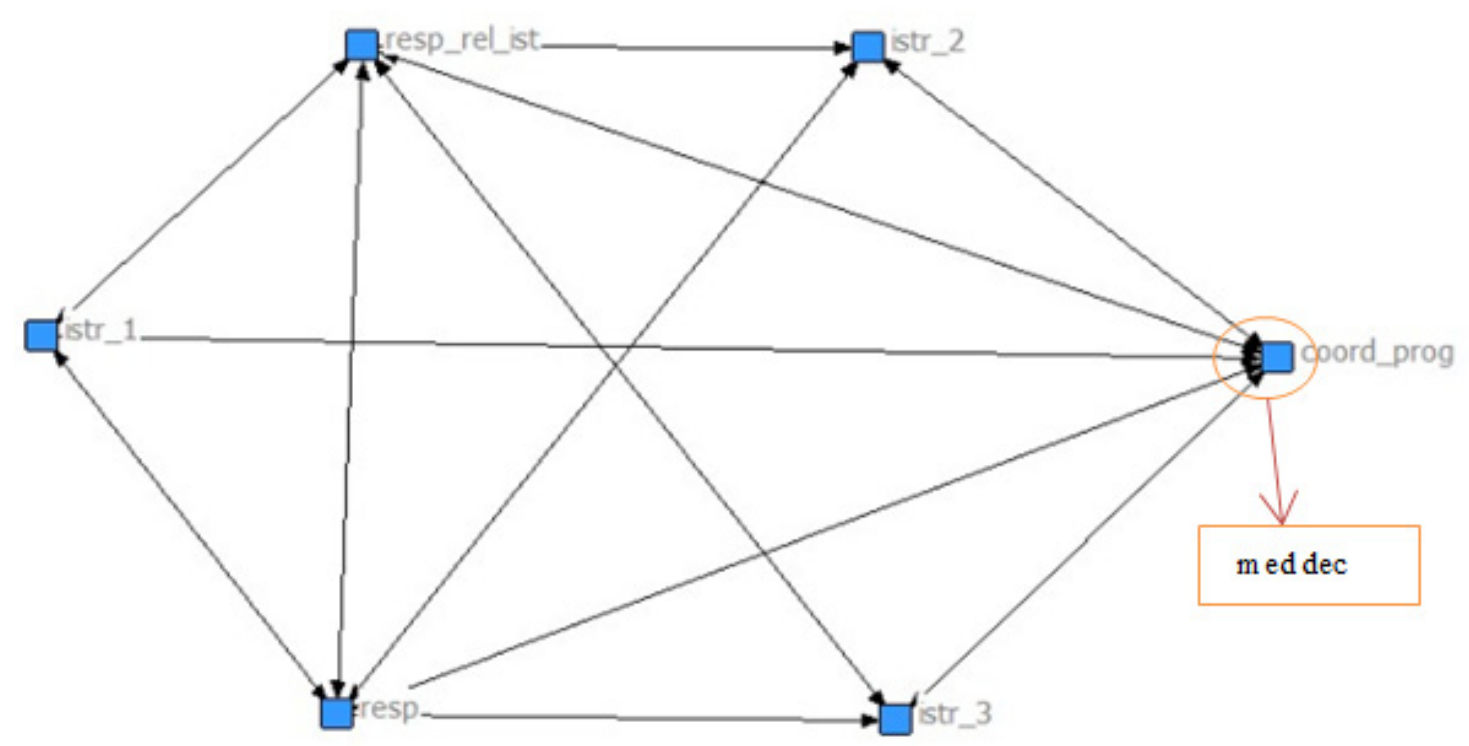

Figure 12. Network of social inclusion Munich

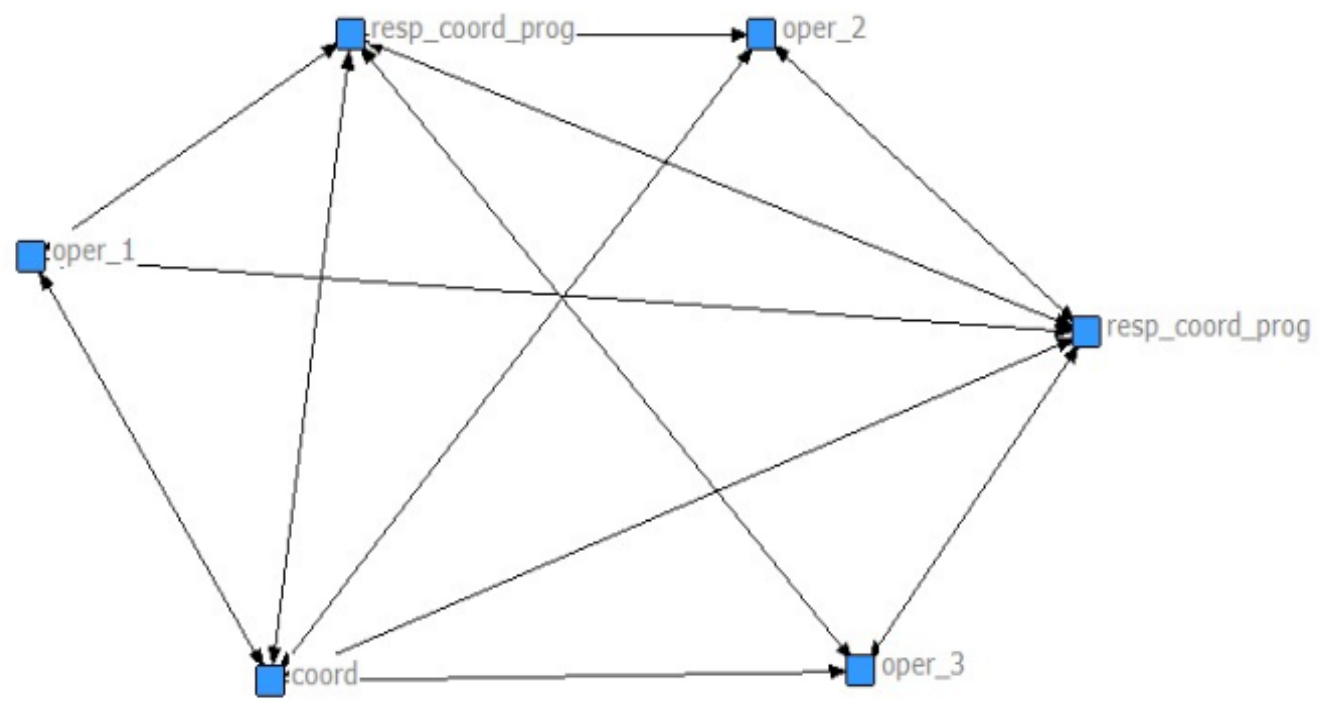

Figure 13. Network of territorial cohesion Munich

Moving to France, in Rouen the network return extended, inclusive, open, dynamic, with loose knit, with no cross-memberships or multiple bonds, structured around a core of primary relationships in the decision-making sphere from which branch openings secondary actors and diversified areas in the positional and reputational spheres. The conflict is revealed and broken down on the side of the procedural and decision-making and are expected many mediators to stem it. The relational configuration, for the network of cohesion, also turns out to be particular, as the same actors conflicting are perceived as the main mediators of the conflict generated by the relational dynamic in the network. Openness, inclusion of the dynamics and the needs of the territory, extension, horizontal structure divided by spheres of influence, are the characters that bring a conformation of issue network less stable and formalized but more elastic and flexible. The actors involved come from different levels of government and governance, as well as implementers and operators, stakeholders, external actors to the specific area of interest, just the desire to recover the soul of a strictly local social policy. Away from it all without a strong trend towards convergence to Unitarian European Welfare System and the leverage of territorial cohesion policy more focused on the development of competitiveness and economic growth. 


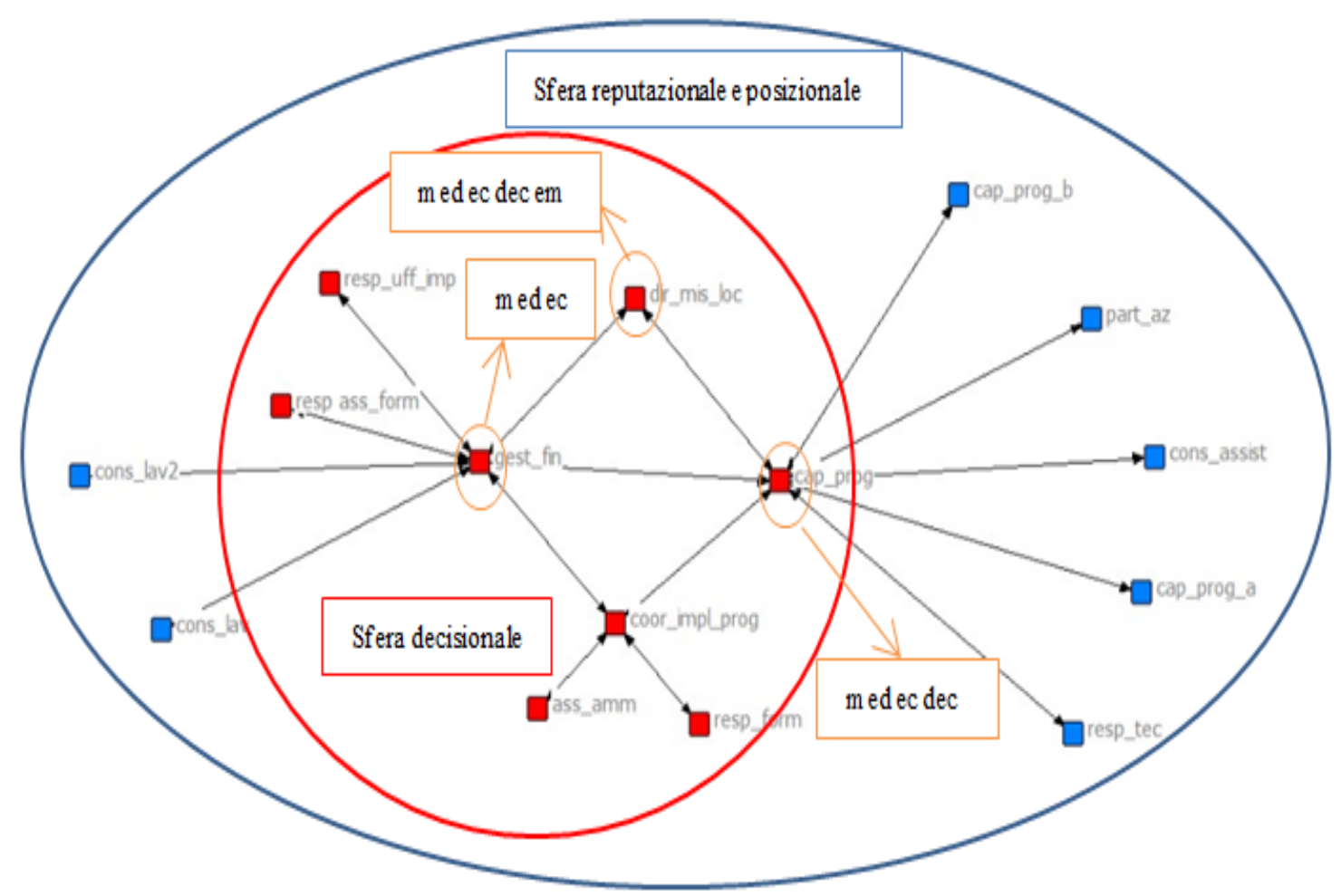

Figure 14. Network of social inclusion Rouen

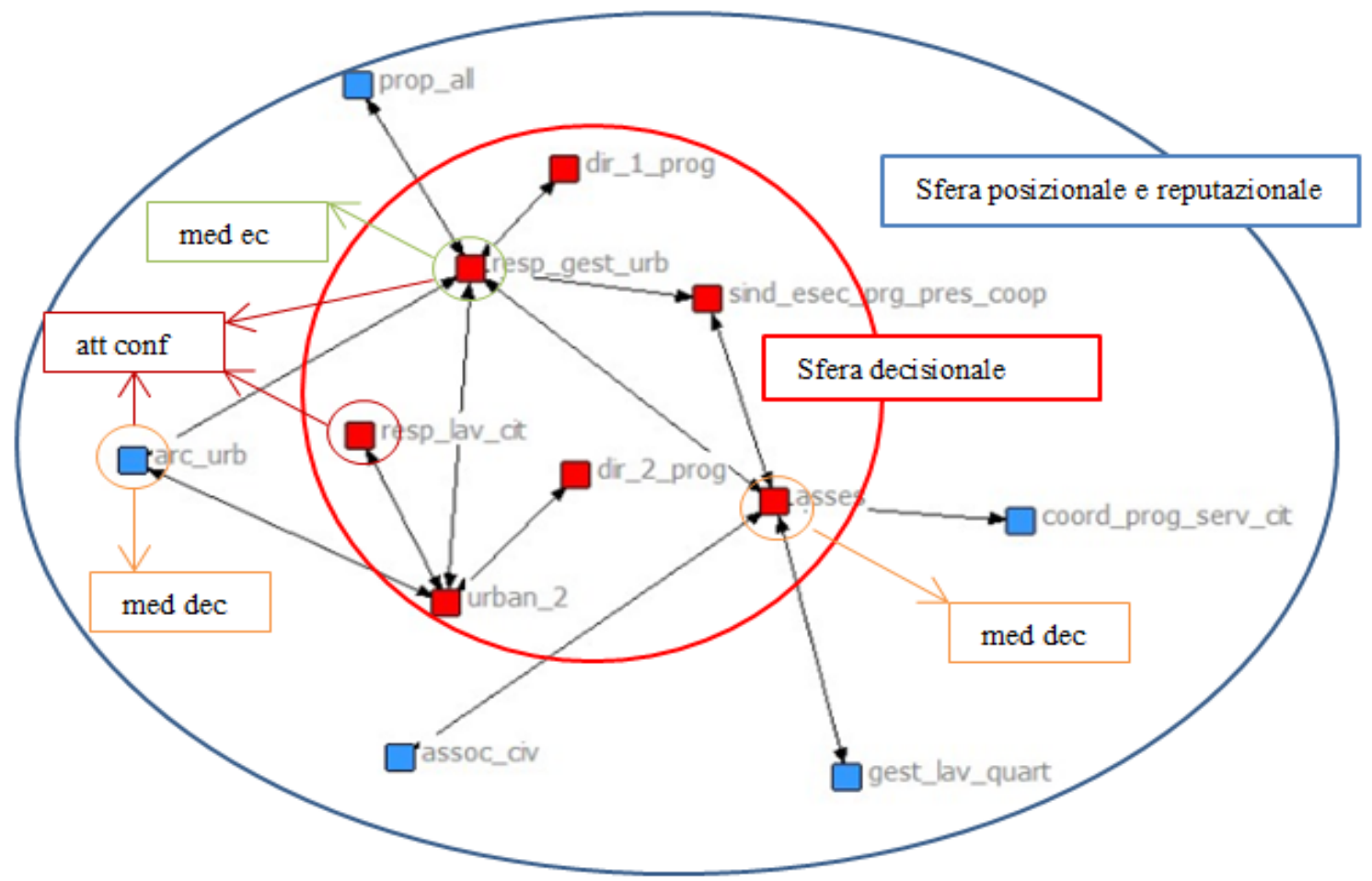

Figure 15. Network of territorial cohesion Rouen

In the UK the situations recorded in London and Liverpool is totally equivalent. These show network based on small cliques of actors maximally connected, without a division into spheres of influence, which manage the different stages and planning responsibilities, with the absence of conflict although figures of mediation are also provided in the networks of London, the figures disappearing neatly into those of Liverpool. Closure, little inclusiveness, narrowness, synergy are the characteristics that lead to the conformation of professionalized network, consisting of operators, implementers and institutional actors in the total absence of stakeholders or actors outside of the scope of the policy 
involved. The prevailing trend is towards a convergent system of Unitarian European Welfare System founded, on contrary to the German and French, on a strong push towards social inclusion policies, a sector that is still lacking, and on which these contexts plans to aim to complete a global development of individual and of territory.

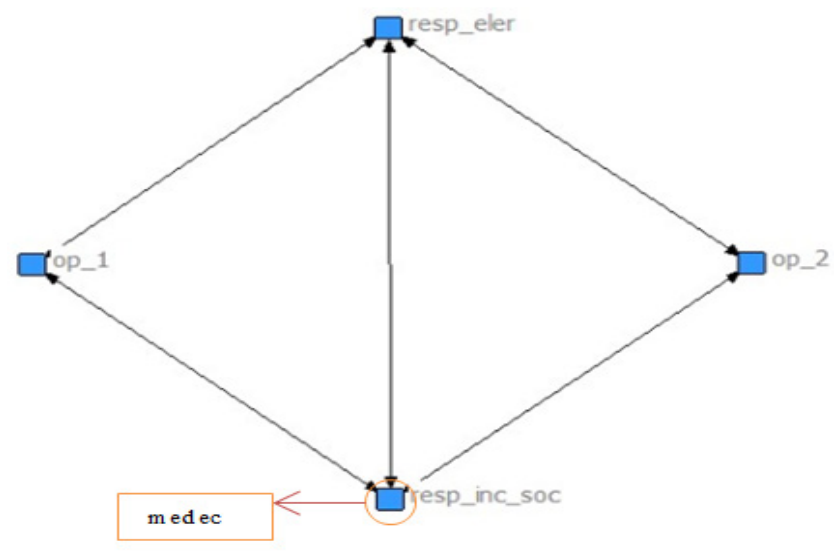

Figure 16. Network of social inclusion London

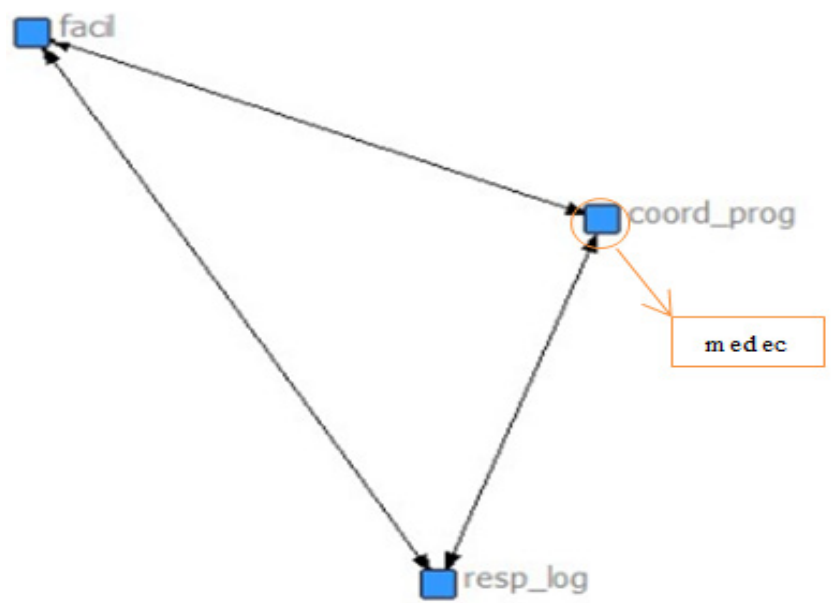

Figure 17. Network of territorial cohesion London

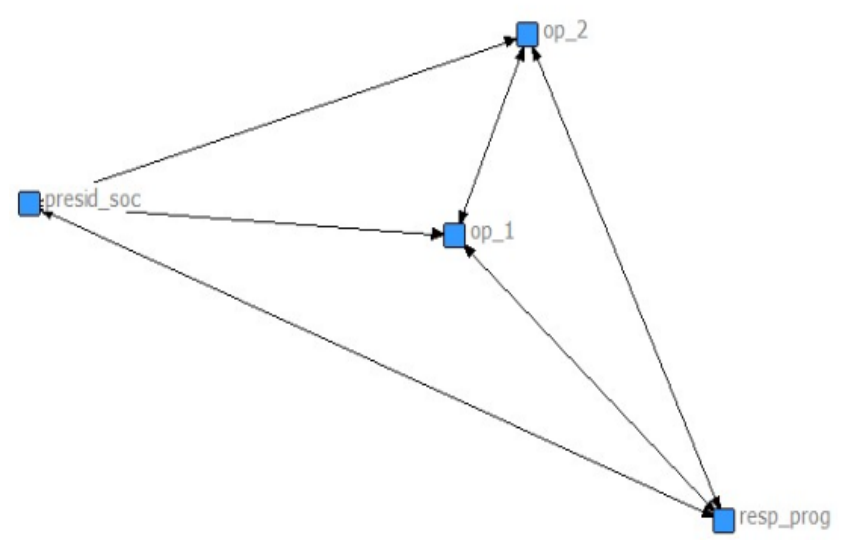

Figure 18. Network of social inclusion Liverpool

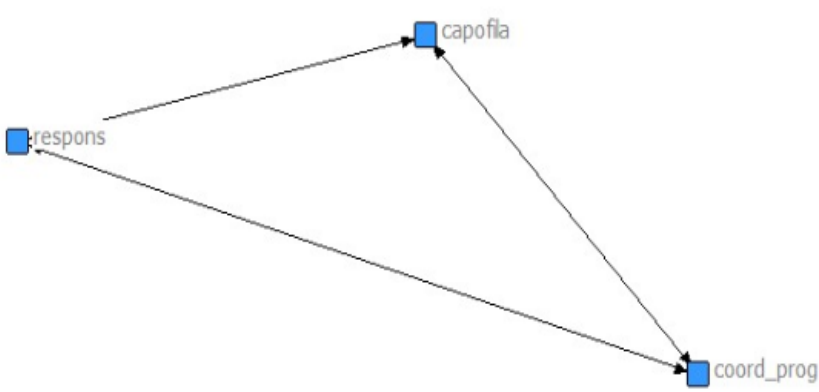

Figure 19. Network of territorial cohesion Liverpool

The last national context analyzed is Spain with Barcelona and Vigo which are maximally interconnected network, tight, cohesive, with crossed affiliations and strong internal concertation with the presence of multiple bonds, which approached to professional relationship see the presence of the parental relationship. Therefore, these networks are inclusive for operational levels, but closed out. In fact, closure, exclusivity and internal concertation both institutional then politic lead to a vertex structure of relationship closer to concerted network with cross-memberships. The conflict is present in the perception of interviewed witnesses, but, nevertheless, it is not specified, or embodied in specific locations or actors. Mediation is, however, expected to be both internally and externally to the network, and it is also important that, in the networks of Vigo, the actor responsible for the checks to be mentioned as influential but has no connection with the actors of the network. Finally, few actors are involved in the network, including implementers, operators, administrative, institutional and representatives of powerful interests, while they are totally absent stakeholders and external actors. For the structural conformation, the networks of Barcelona are very similar to those in Germany, while those of Vigo are very close to those recorded in the Anglo-Saxon context. However, to differentiate them is the nature of the ties that binds the actors, multiple bonds and extremely strong, but especially the fact that they are always the same subjects, regardless of the scope of the policy in question, to maneuver decision, implementation and exercise of power in territorial development of social policy. Even if the network in question appear to be so strongly associated in each area of policy, the local dynamics leading to the emergence of a regime closer to the local net welfare, mostly aimed at the territorial cohesion policy, in which the context, limited by law, but stimulated procedurally and strategies implementation, becomes the responsible entity of the broad welfare, rather than delegate supranational actor, leaving that this last push it towards a furcated convergence at which the territory is not ready yet. 


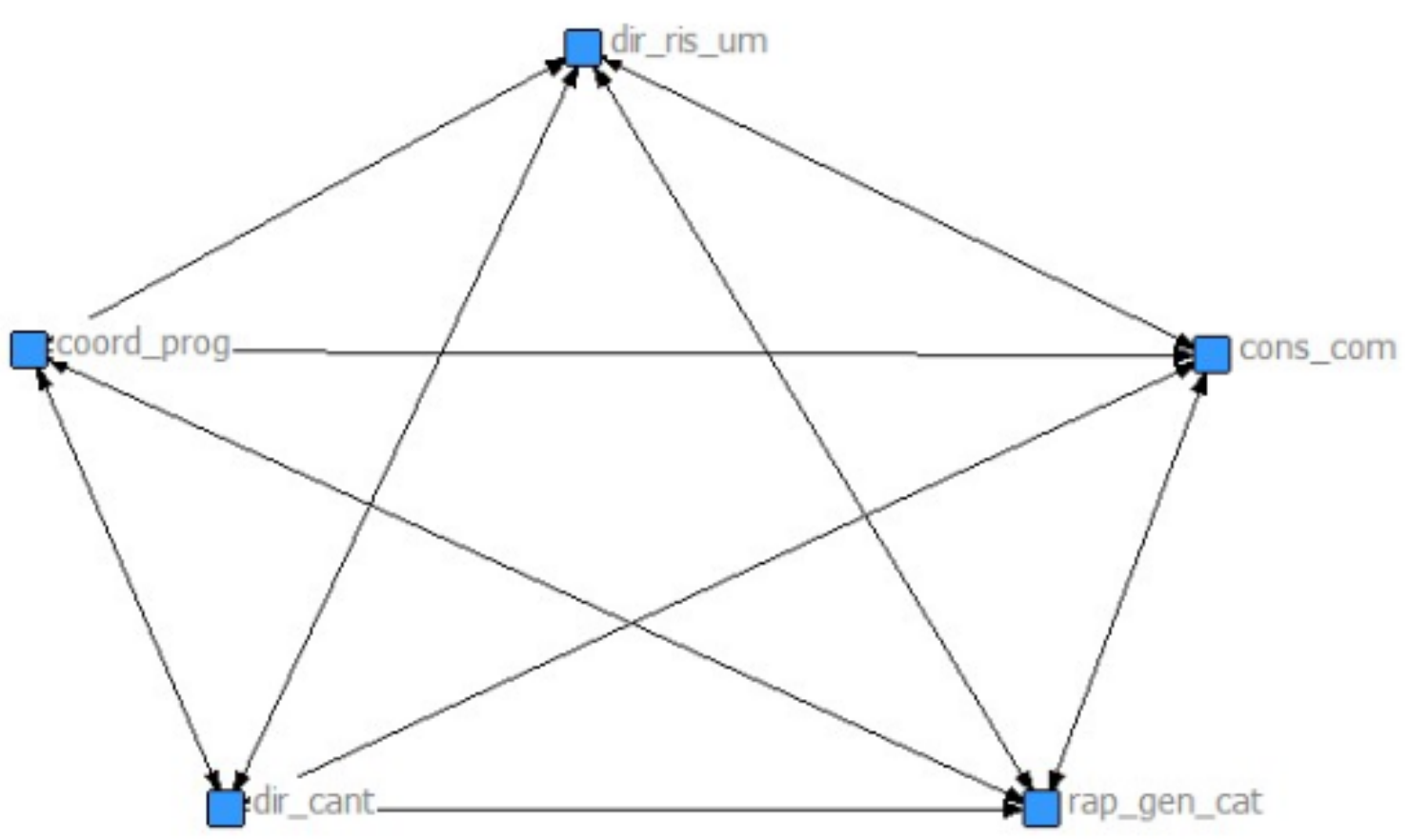

Figure 20. Network of social inclusion Barcelona

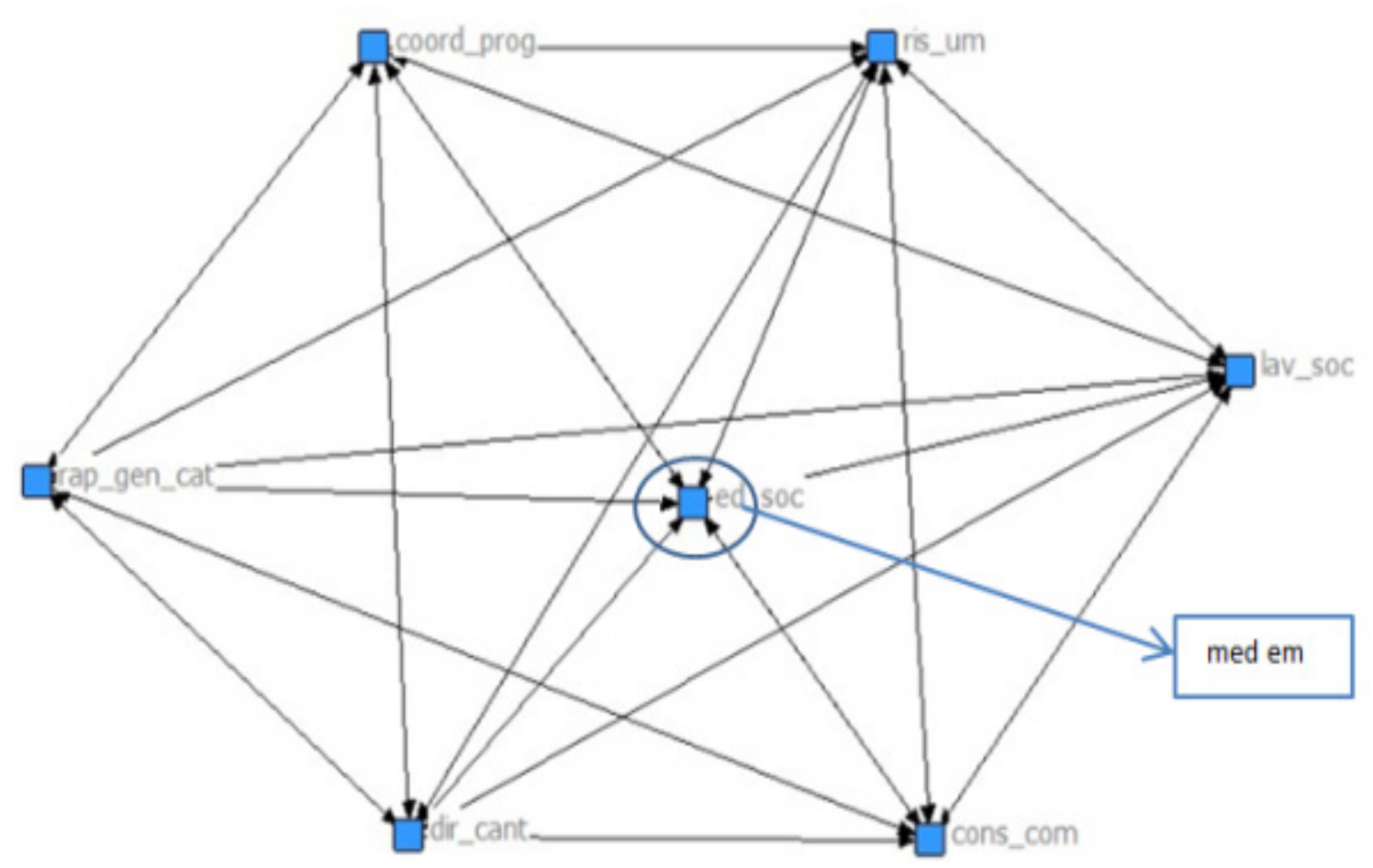

Figure 21. Network of territorial cohesion Barcelona 


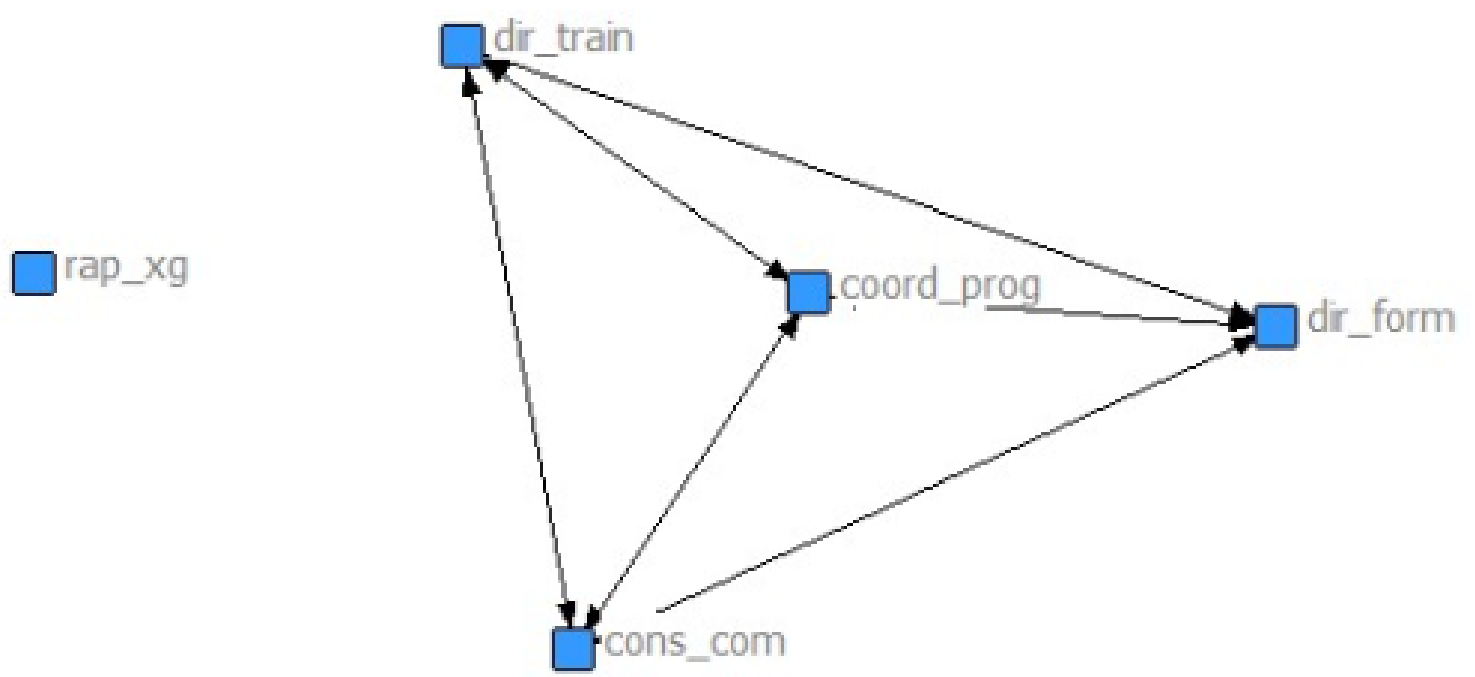

Figure 22. Network of social inclusion Vigo

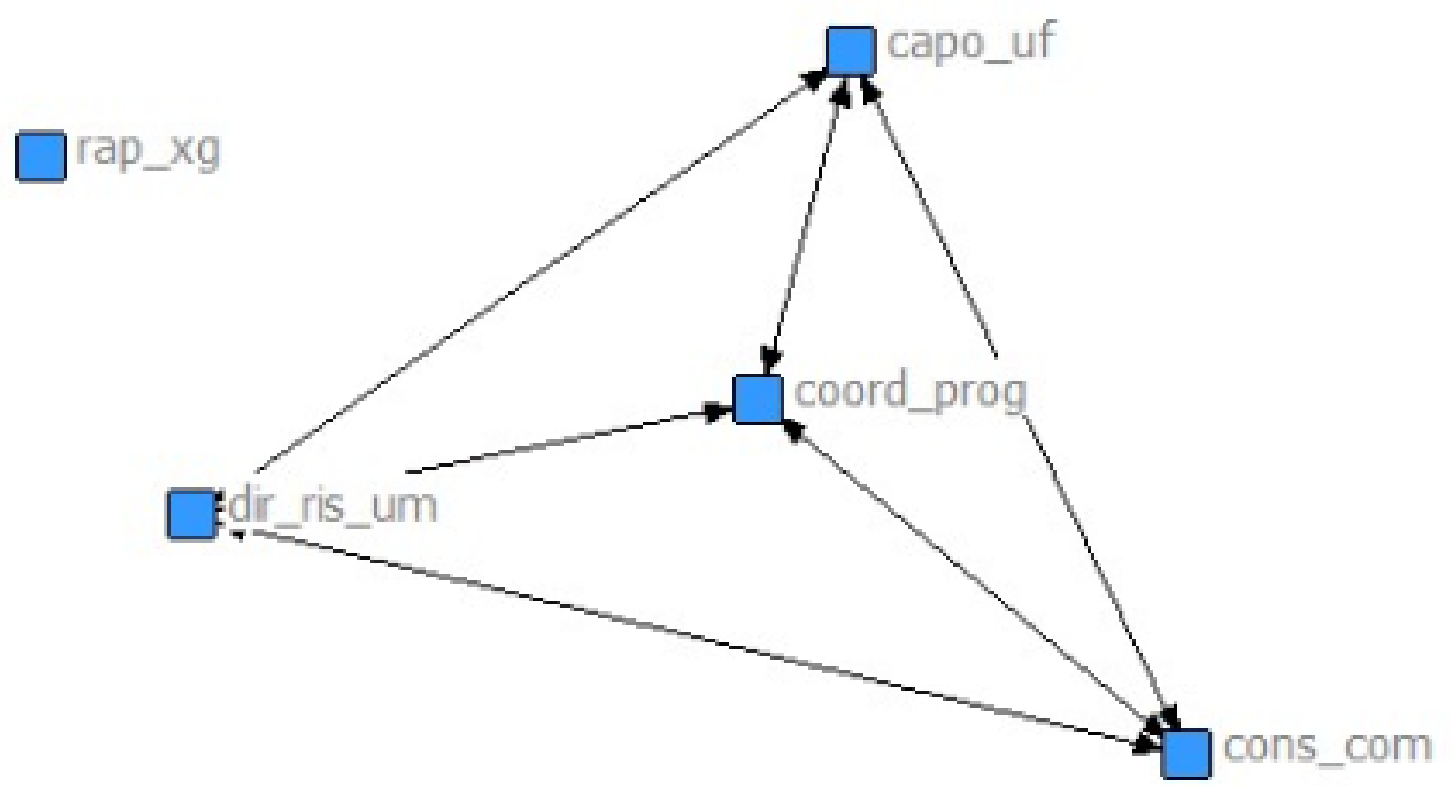

Figure 23. Network of territorial cohesion Vigo

The different relational patterns detected shows that it is not the structure of relationships to influence the field (think of the structural similarities between Naples, Berlin and Barcelona, or between London and Vigo, or even between Milan and Rouen), but are the actors in it involved with their roles and positions, to give life to different implementations.

\section{Conclusions: The General Model of Classification}

The presented results represent an evolving typology, born from a pilot study, currently completed and tested in its specific parts. The conclusions that have been reached led the characteristics of project implementation, the conformations and the propensity to particular types of networks, to be screened in the space of attributes built in macro analysis stage. This is to complete the necessary details the proposed general model of classification and clearly demarcate systems emerged and directions of integration which give rise. What emerges are two new polarities, issue networks vs. policy community [52] and professionalized network e concerted network with cross-memberships, and both transversely across the built quadrants.

The quadrant of the Confluence, therefore, in addition to detecting the converging trend towards a European welfare and the propensity for territorial cohesion policy continues to be characterized by the presence of network intended as policy community, closed tight, cohesive and highly structured, embodied in the Germans contexts.

At the center of this new polarization and therefore also at the center of the space of attributes, there are French contexts, midway between the strong cohesion and the evolution of the network towards the issue networks intended as open and dynamics network, inclusive and extensive fully embodied 
the extreme polarity contexts such as Milan. We are therefore in the quadrant of Emergence that intersects the local net welfare systems and propensity for local social inclusion policies. An exception in this quadrant is the Neapolitan context, which shows that the more we move away from the center the more extreme the local net welfare systems aimed at local characterizations may show quite unexpected. In this context, the network back to being closed, not inclusive and based on lobbyist dynamic, a clear expression of the fact that it is moving more and more towards convergence by reference to the implementation of social policy as a dimension purely contextual and local. This Italian bifurcation is not trivial, since it shows the organizational and territorial management and differentiated systems of local net welfare systems.

In the quadrant that intersects trends towards local net welfare systems and propensity to social cohesion policies, the quadrant of Development, we find the Spanish contexts, which are to be characterized by having locally developed networks and concerted strongly characterized by the presence of the cross membership to more areas of policy, resulting, therefore, confined, highly cohesive, selected and interconnected. Also in this case the trends is strong to autonomy, marking the distance from the path to convergence, as they are the same local contexts, already burdened by economic and social crisis, not to lend itself to systematic and standardized implementations of social policy, and so because they are the place of foothold and deep knowledge of the territory on which it is implemented.

In the last quadrant, that of Stabilization, consisting of the intersection between regimes aimed at the convergence to the European welfare and propensity towards social inclusion policies, the strategy of the network that is to emerge is that of professionalized networks, grids extremely narrow actors, from ties not strong but functional objective, purpose networks that tend to maximize the local impact of social policy conceiving the implementation process as a process professionalized and highly specialized, so as to involve the "minds" (managers and institutional actors) rather than the "arms" (operators and implementers) in the process of local implementation of social policy, inverse dynamics to German speculate, however, tended to convergence.

The typology, so set-up, it reveals its character as an integrated tool that includes the results of different analytical methods to make them into an overall system. This typology can be understood as a tool for reading the changes taking place in the differences and in the trends that pervade the current welfare systems. It offers interpretive categories and insights useful to expand and retrofit of additional elements the same typological tool of interpretation generated, as in continuous evolution and ready to pick up the change and make it a systemic integral variable.

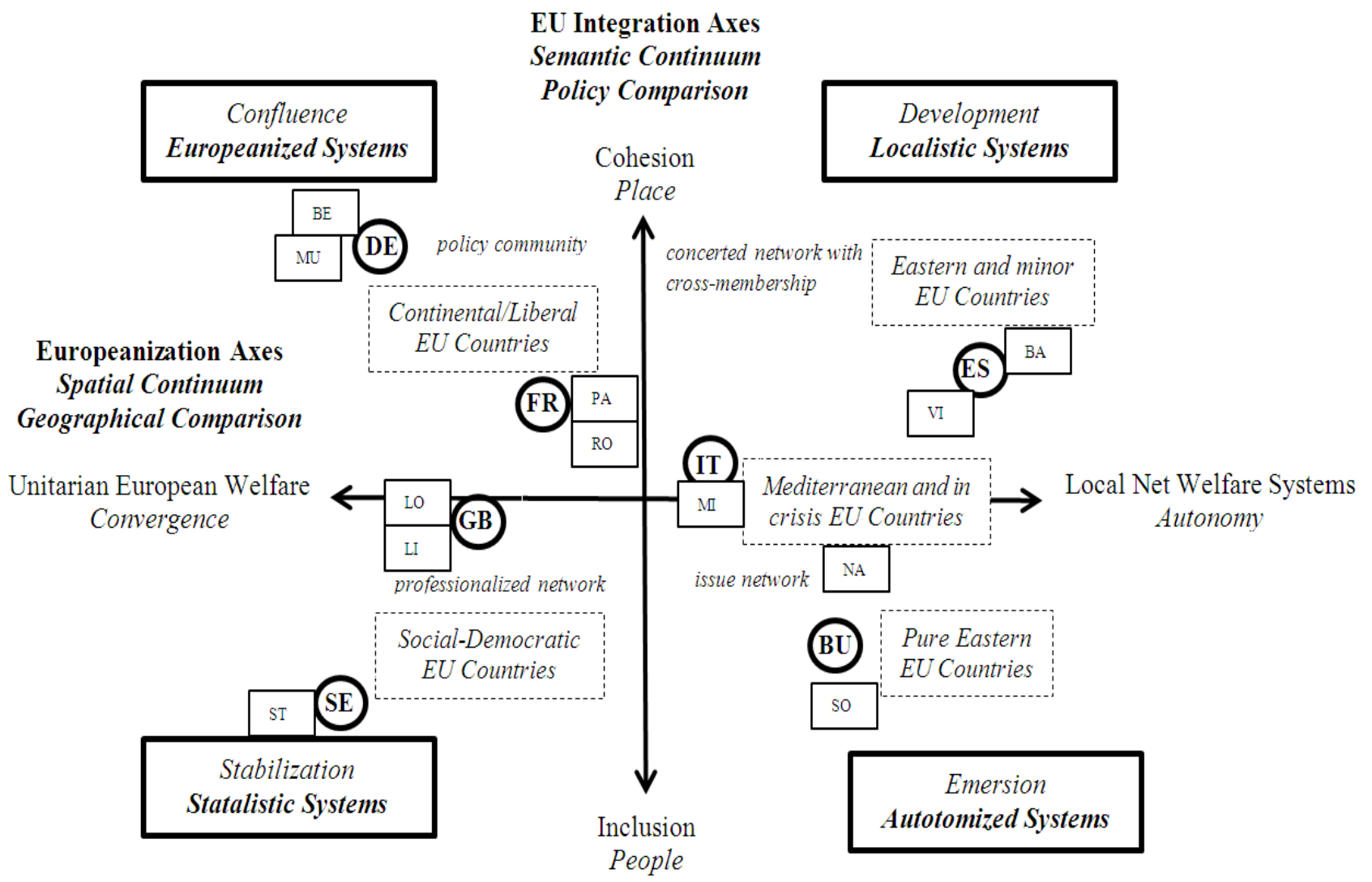

Figure 24. General Model of Classification with the overlap of all the elements emerged from the different steps of analysis. 


\section{REFERENCES}

[1] Punziano G. Welfare europeo o welfare locali?: i processi decisionali nel sociale tra convergenza ed autonomia; 2012.

[2] Esping-Andersen G. Welfare states in transition. London: Sage; 1996.

[3] Leibfried S, Pierson P. European Social Policy: The Development of Social Europe. Semi sovereign Welfare States: Social Policy in a Multitier Europe: Brookings Institution; 1995.

[4] Le Galès P. European Cities: Social Conflicts and Governance: Social Conflicts and Governance: Oxford University Press; 2002.

[5] Guillén AM, Palier B. Introduction: Does Europe matter? Accession to EU and social policy developments in recent and new member states. Journal of European Social Policy. 2004; 14(3):203-9.

[6] Giuliani M. Europeizzazione come istituzionalizzazione: questioni definitorie e di metodo. Rivista italiana di politiche pubbliche. 2004; 1: 141-61.

[7] Ferrera M, Maino F. Le politiche sociali: L'Italia in prospettiva comparata: Il mulino; 2006.

[8] Naldini M. Le politiche sociali in Europa: trasformazioni dei bisogni e risposte di policy: Carocci; 2006.

[9] Negrelli S, De Leonardis O, Salais R. Democracy and capabilities for voice. Welfare, Work and Public deliberation in Europe. 2012.

[10] Kazepov Y, Arlotti M, Barberis E. La de-sincronizzazione, il disallineamento e la frammenta zione territoriale delle politiche sociali. Alcune considera zioni preliminari. Kazepov Y, a cura di (2009), La dimensione territoriale delle politiche sociali in Italia, Carocci. 2009:247-54.

[11] Kazepov Y. Rescaling social policies: towards multilevel governance in Europe: Ashgate Publishing, Ltd.; 2010.

[12] Bifulco L. Le politiche sociali. Temi e prospettive emergenti, Carocci, Roma. 2005.

[13] Featherstone K, Radaelli CM. The politics of Europeanization: Oxford University Press; 2003.

[14] Giuliani M. Op. cit. 2004.

[15] Börzel TA, Risse T, editors. One size fits all! EU policies for the promotion of human rights, democracy and the rule of law. Workshop on Democracy Promotion; 2004.

[16] Mörth U. Europeanization as interpretation, translation, and editing of public policies. The politics of Europeanization. 2003:159-78

[17] Donzelot J. Faire sociâetâe: la politique de la ville aux Etats-Unis et en France: Seuil; 2003.

[18] Punziano G. Op. cit. 2012.

[19] Titmuss RM. Social policy: Allen \& Unwin London; 1974.
[20] Esping-Andersen G. The three worlds of welfare capitalism. Cambridge, Policy Press; 1990.

[21] Ferrera M. The 'Southern model' of welfare in social Europe. Journal of European social policy. 1996(6):17-37.

[22] Ferrera M. Op. cit. 2006.

[23] Naldini M. Op. cit. 2007.

[24] Nussbaum M, Sen A. The quality of life: Oxford University Press; 1993.

[25] Paci M. Welfare, solidarietà sociale e coesione della società nazionale. Stato e mercato. 2008(1):3-30.

[26] Ferrera M. Op. cit. 2006.

[27] Donolo C, Bifulco L. Il futuro delle politiche pubbliche: Bruno Mondadori; 2006

[28] Naldini M. Op. cit. 2007.

[29] Kazepov Y, Arlotti M, Barberis E. Op. cit. 2009.

[30] Ferrera M. Op. cit. 2006.

[31] Beck U. Risk society revisited: theory, politics and research programmes. The risk society and beyond: Critical issues for social theory. 2000:211-29.

[32] Teddlie C, Tashakkori A. Major issues and controveries in the use of mixed methods in the social and behavioral sciences. Handbook of mixed methods in social \& behavioral research. 2003:3-50.

[33] Teddlie C, Yu F. Mixed methods sampling a typology with examples. Journal of mixed methods research. 2007;1(1):77-100.

[34] Creswell JW. Qualitative inquiry and research design: Choosing among five approaches: Sage; 2012.

[35] Creswell JW. Research design. Qualitative, quantitative and mixed methods approaches 2nd edition EUA Sage. 2003;196.

[36] Punziano G. Op. cit. 2012.

[37] Punziano G. Op. cit. 2012.

[38] Pearson K. Principal Components Analysis the London, Edinburgh, and Dublin Philosophical Magazine and Journal of Science. 1901; 6(2):559.

[39] Hotelling H. Analysis of a complex of statistical variables into principal components. Journal of educational psychology. $1933 ; 24(6): 417$.

[40] Hox J. Multilevel analysis: Techniques and applications: Routledge; 2010.

[41] Esposito Vinzi V. PLS path modeling and PLS regression: a joint partial least squares component-based approach to structural equation modeling. IFCS@GFKL-Classification as a Tool for Research (IFCS 2009). 2009.

[42] Esposito Vinzi V. Trinchera L, Amato S. PLS path modeling: from foundations to recent developments and open issues for model assessment and improvement. Handbook of partial least squares: Springer; 2010. p. 47-82. 
[43] Ferrera M. Le trappole del welfare. Uno stato sociale sostenibile per l'Europa del XXI secolo. Il Mulino, Bologna. 1998.

[44] Kazepov Y, Arlotti M, Barberis E. Op. cit. 2009.

[45] Bifulco L. Op. cit. 2005.

[46] Graziano P. Europeizzazione e politiche pubbliche italiane: coesione e lavoro a confronto: Il mulino; 2004.

[47] Graziano P. Op. cit. 2004.

[48] Graziano P. Op. cit. 2004.
[49] Scott J, Amaturo E. L'analisi delle reti sociali: La Nuova Italia Scientifica; 1997.

[50] Wasserman S, Faust K. Social network analysis: Methods and applications: Cambridge university press; 1994.

[51] Wamsley GL, Milward B. Policy Subsystems: Networks and the Tools of Public Management. By Robert Eye-stone JAI Press Wamsley Policy Subsystems: Networks and the Tools of Public Management 1984. 1984.

[52] Marin B, Mayntz R. Policy networks: Empirical evidence and theoretical considerations: Campus Verlag; 1991. 